\title{
Unmögliches Erzählen. Franz Kafkas Der Bau
}

\section{Ordnung ist ein zentrales Thema in Leben und Werk Franz Kafkas. ${ }^{454}$ Kann} Theodor Fontane als Vertreter von Ordnung gelten und Robert Walser als Experte des Unordentlichen, so befindet sich Kafka - sowohl biografisch wie in seinem Werk - im Brennpunkt sich ausschließender Ordnungen. Die Erwerbstätigkeit und die Literatur, die Zweifel an seinem Vermögen und die Ansprüche an sich, die Erwartungen der Herkunft und der eigene Lebensentwurf, das säkulare Judentum seiner Familie, der Druck der Assimilation und die ,ostjüdische Inspiration' in der Figur des Schauspielers Löwy - dies alles waren gegensätzliche Ordnungen, deren Reibung Kafka in einer Zeit auszutragen hatte, in der die zunehmenden historischen Veränderungen eine tiefgreifende Verunsicherung der Ordnung und deren Verlässlichkeit bewirkte. Nicht zuletzt war Prag, wo Kafka den Großteil seines Lebens verbrachte, von Prozessen der Desintegration geprägt. ${ }^{455}$ In seiner Tätigkeit als Jurist in der Arbeiter-Unfall-Versicherungsanstalt in Prag war Kafka selbst direkt daran beteiligt, Ordnung zu schaffen, indem er Verhaltensrichtlinien für die versicherten Arbeiter konzipierte. Die Bürokratisierung als groß angelegter und entschieden

454 In diesem Kontext verortet auch Peter-André Alt das Projekt seiner Kafka-Biografie: „Zentrale Aufgabe dieses Buchs ist es daher, die Prägungen zu beschreiben, die das Leben durch die imaginären Welten der Poesie und die Formen ihrer inneren Ordnung empfangen hat. Erst die Einsicht in die literarische Konditionierung der Erfahrung erschließt das geheime - keineswegs mythische, vielmehr bewußt produzierte - Gesetz, das Kafkas Vita machtvoll regiert. In ihr existieren keine einfachen Lösungen, sondern nur Paradoxien und dialektische Verstrickungen, denen traditionelle Mythen wie das Bild vom asketischen, lebensängstlichen Schriftsteller so wenig gerecht werden wie ihre programmatischen Entzauberungen." Peter-André Alt, Franz Kafka. Der ewige Sohn. Eine Biographie (München: C. H. Beck, 2005), 15.

455 Die allgemeine Entwicklung Prags beschreibt Ernst Pawel in seiner Biografie zu Kafka wie folgt: „But the old order, with its timeless patterns and steady pace, was rapidly disintegrating. The rural community, where a man's roots reached back for generations, and where he was both trapped and protected by an intricate network of lifelong entanglements, crumbled under the onslaught of industrialization and urbanization." Ernst Pawel, The Nightmare of Reason. A Life of Franz Kafka (London: Harvill Press, 1984), 21. Pawel bezieht sich hier vorerst auf das frühe 19. Jahrhundert, das durch das Aufkommen der Nationalstaaten geprägt wurde und präzisiert diese Bewegung für die Lebensbedingungen und die Herkunft Kafkas. Allgemein lässt sich diese Beschreibung auf die Jahrhundertwende und darüber hinaus als eine Situation der Umbrüche von Ordnungen beziehen. 
ausgeführter Ordnungsversuch erlebte und förderte Kafka in seiner Funktion in gewissem Sinn also mit. ${ }^{456}$ Auch die Ordnungen des bürgerlichen Lebens und des Künstlerlebens standen in Konflikt zueinander: Zum einen verfolgte Kafka den Versuch, sich durch eine Heirat bürgerlich zu etablieren, zum anderen war da die Hinwendung zum asketischen Leben als Schreibender. Dieser Konflikt war eines der zentralen Themen im Briefwechsel mit Felice Bauer.

Wie Robert Walser gilt Kafka als Autor, bei dem Leben und Werk eins sind. ${ }^{457}$ In der Selbstdarstellung verschmilzt die Identität mit der Literatur, wie es Kafka im vielzitierten Brief an Felice Bauer formuliert: „Ich habe kein litterarisches Interesse sondern bestehe aus Litteratur, ich bin nichts anderes und kann nichts anderes sein.“458 Dass dieser enge Bezug von Leben und Werk nicht autobiografisches Schreiben nach sich ziehen muss, versteht sich von selbst. In seinem Werk zeigt er sich geradezu besessen von Ordnungen, deren Darstellung und Verhandlung, in genussvoller bis sadistischer Elaboration, in vielen Texten im Zentrum stehen.

Schon in Das Urteil (1913) wird eine mächtige Ordnung des Vaters beschrieben. ${ }^{459}$ Die Verwandlung (1916) erweitert und variiert die Ordnung des Vaters um das Familiengefüge, die Arbeitswelt, die Opposition von Mensch und Tier. Auch die räumliche Ordnung, die beim Urteil ebenfalls eine wichtige Rolle

456 Zur Funktion der Bürokratie bei Kafka, insbesondere auf den Bau bezogen, vgl. Richard Heinemann, „Kafka's Oath of Service: ,Der Bau' and the Dialectic of Bureaucratic Mind“, PMLA 111, Nr. 2 (März 1996): 256, https://doi.org/10.2307/463105.

457 Für eine Übersicht über die Biografien zu Franz Kafka: Christian Klein, „Kafkas Biographie und Biographien Kafkas“, in Kafka-Handbuch. Leben - Werk - Wirkung, hg. von Oliver Jahraus und Bettina von Jagow (Göttingen: Vandenhoeck \& Ruprecht, 2008), $18-36$. Klein stellt fest: „Wer Kafka liest, so der Eindruck, setzt sich immer auch mit dessen Biographie auseinander." Klein, 17.

In Bezug auf Robert Walser schreibt Lucas Marco Gisi: „Robert Walser ist in seinem Werk in geradezu paradoxer Weise gleichzeitig äußerst präsent und vollkommen verborgen. Dass Leben und Werk in seinem Fall derart ineinander zu greifen scheinen, ist nicht bloß die Folge einer Rezeptionshaltung, die Texte und Biographie kurzschließt, sondern selbst Effekt eines spezifischen Darstellungsverfahrens. Dies äußert sich vor allem darin, dass dieser Bezug - mal affirmativ, mal abwehrend - in Walsers Texten selbst ständig thematisch wird.“ Gisi, „Leben und Werk “', 1.

$45^{8}$ Brief 590 an Felice Bauer in Westerland auf Sylt, 14.8.1913, in: Franz Kafka, Briefe. 1913-März 1914, in Franz Kafka. Schriften Tagebücher Briefe. Kritische Ausgabe, hg. von Jürgen Born u. a., Bd. hg. von Hans-Gerd Koch (Frankfurt am Main: Fischer, 1999), 261.

459 Das Urteil wurde im von Max Brod herausgegebenen Band Arkadia. Jahrbuch für Dichtkunst bei Kurt Wolff in Leipzig veröffentlicht, wo auch Walser mit vier Texten vertreten war. Walser dürfte Das Urteil also gekannt haben; in den Wanderungen schreibt Seelig, Walser habe auf Seeligs Bemerkung, er habe „seine Beliebhteit in Prag wohl auch Franz Kafka zu verdanken“ kaum reagiert: „Aber Robert winkt ab; er kenne Kafkas Werke kaum.“ Seelig, Wanderungen mit Robert Walser, $54 \mathrm{f}$. 
spielt, wird im Grundriss der Wohnung der Familie Samsa weiter differenziert. Der Brief an den Vater (verfasst 1919) ist eine Analyse und Modellierung der patriarchalischen Ordnung hinsichtlich der Beziehung zwischen Vater und Sohn.

Die Erzählung In der Strafkolonie modelliert den Konflikt zwischen der Ordnung des alten und des neuen Kommandanten. Durch den fremden Reisenden werden sie als kolonialistische Ordnungen lesbar. ${ }^{460}$ Der Apparat, Repräsentant der alten Ordnung, soll nach Aussage des alten Offiziers absolut gerecht sein, da er den Richtspruch in den Körper des Verurteilten ritzt, so dass dieser dadurch seine Schuld erkennen soll. Als der Reisende die Bitte ablehnt, für die Maschine beim neuen Kommandanten Partei zu ergreifen, liefert sich der alte Kommandant selbst der Maschine aus. Doch deren mechanische Objektivität versagt, sie zerfällt und tötet ihn, ohne einen Schuldspruch in den Körper einzuritzen. Die Maschine als Meta-Metapher, Machtapparat und totalitäre „Schreckenssignatur des 20. Jahrhunderts“ wird in ihrer Fähigkeit, Ordnung zu schaffen, zu erzwingen und zu unterbinden, in großer Effektivität dargestellt. ${ }^{461}$

Die Ordnungsproblematik wird bei Kafka dominant in der räumlichen Gestaltung aufgegriffen. Insbesondere in der Architektur und Topografie von Landschaften zeigt sich die doppelbödige Anlage, die Ordnung erzeugt und gleichzeitig aufhebt. ${ }^{462}$ Das verwinkelte Gerichtsgebäude des Romanfragments Der Proceß (verfasst 1914/1915, posthum erschienen 1925) etwa dient mit seinen komplizierten Strukturen als Spiegelung des Prozesses, dem K. unterzogen wird. Die bürokratische und juristische Ordnung wird gleichsam in der Architektur wirksam. In Das Schloß (verfasst 1922, posthum erschienen 1926) wird das Dorf dem Schloss programmatisch gegenübergestellt. Die Überwindung der Grenze zwischen Dorf und Schloss gelingt nur Ausgewählten. Regelmäßig werden jedoch auch diese Grenzziehung und die Zuordnung der Figuren zu einer der Seiten untergraben und verunsichert. Auch die Darstellung von Innenräumen ist undurchsichtig, zuweilen labyrinthisch und

46o Paul Peters, „Witness to the Execution: Kafka and Colonialism“, Monatshefte 93, Nr. 4 (2001): 401-425. Vgl. zum Aspekt der Ethnologie Gerhard Neumann, Franz Kafka - Experte der Macht, Edition Akzente (München: Hanser, 2012), 195-218.

461 Alexander Honold, „In der Strafkolonie“, in Kafka-Handbuch. Leben - Werk - Wirkung, hg. von Bettina von Jagow und Oliver Jahraus (Göttingen: Vandenhoeck \& Ruprecht, 2008), 477 .

462 Vgl. „Wenn man einmal darauf aufmerksam geworden ist, dann gehen einem die Augen auf: Franz Kafkas ganzes Werk ist durchzogen von Vorstellungen und Argumenten der Architektur." Gerhard Neumann, "Chinesische Mauer und Schacht von Babel. Franz Kafkas Architekturen“, in Kafka-Lektüren (Berlin, Boston: De Gruyter, 2012), 482, https:// doi.org/10.1515/9783110288759. 
bringt die Differenzierung von Innen und Außen, aber auch von Raum und Raumwahrnehmung durcheinander.

Diese Teilung des Raums in zwei Bereiche mittels Grenzziehung, die scheinbar eine stabile Ordnung etabliert, wird in zahlreichen Texten Kafkas dekonstruiert. Ein Beispiel ist Kafkas Eine kaiserliche Botschaft (1919), bzw. der posthum veröffentlichte Text Beim Bau der Chinesischen Mauer (1931), in dem eine ins Unendliche verräumlichte und verzeitlichte Grenzziehung dargestellt wird: Innen und Außen werden einerseits inszeniert und andererseits verunsichert.

Häufig wird gerade in den Kurztexten eine dynamisierte Umkehrung der Ordnung zum eigentlichen Thema. In Auf der Galerie (1919) wird zunächst eine Differenzierung zwischen Täter (Zirkusdirektor und Chef) und Opfer (Kunstreiterin) in einem Konditionalsatz etabliert, die dann verunsichert wird. Dadurch wird die erzählte Geschichte ambivalent. Die Destabilisierung von Ordnung wird nicht zu einer neuen Ordnung fixiert, sondern im Unbestimmten belassen. Die Bildlichkeit Kafkas ist auch in diesem Fall nicht statisch, sondern entfaltet eine implizite narrative Dynamik. ${ }^{463}$

Dem zentralen Thema Ordnung nimmt sich Kafka im ,Bau'-Konvolut in geradezu programmatischer Weise an: In Der Bau ist die räumliche Metapher für die Ordnung sozusagen exklusiv aktiv als Reflexion der eigenen Erzählordnung. Das zentrale Wort „Bau“, das in der Erzählung unzählige Male vorkommt, zeigt dies in seiner Vieldeutigkeit an: Unter anderem bedeutet Bau auch Konstruktion und Struktur. ${ }^{464}$ Der Begriff steckt gleichsam die Vieldeutigkeit des Textes ab und veranschaulicht die ambivalente Position, in der sich der Erzähler in seinem Bau befindet.

Das ,Bau'-Konvolut endet mit einem abgebrochenen Satz am Ende eines vollgeschriebenen Blattes, den Max Brod in seiner Ausgabe durch einen minimalen, aber wirkungsvollen Eingriff vervollständigte. Dies führte zur Annahme, beim Text handle es sich um ein Fragment. ${ }^{465}$ Geschrieben hat Kafka

463 Vgl. dazu etwa Hans Hiebel in Bezug auf den Proceß: „Das Romanfragment Der Proceß ist gewissermaßen nichts weiter als die Ausweitung einer Parabel, der ,Legende Vor dem Gesetz [...]. Kafkas Metapher des ,Gerichts‘ bzw. ,Prozesses‘ ist eine verdichtete bzw. sukzessive von Sinnbeziehung zu Sinnbeziehung ,gleitende‘ Metapher." Hans H. Hiebel, „Der Proceß / Vor dem Gesetz“, in Kafka-Handbuch. Leben - Werk - Wirkung, hg. von Bettina von Jagow und Oliver Jahraus (Göttingen: Vandenhoeck \& Ruprecht, 2008), 456.

464 Jacob Grimm und Wilhelm Grimm, „Bau“, in Deutsches Wörterbuch von Jacob Grimm und Wilhelm Grimm (Leipzig, 1853), http://www.woerterbuchnetz.de/DWB?lemma=bau.

Siehe Kap. 4.1.2 Ambivalenz in der Differenzierung, S. 207ff. unten.

465 Vgl. dazu Franz Kafka, Nachgelassene Schriften und Fragmente II. Appartband, in Franz Kafka. Schriften Tagebücher Briefe. Kritische Ausgabe, hg. von Jürgen Born u. a., Bd. hg. von Jost Schillemeit (Frankfurt am Main: Fischer, 1992), 142. Es gibt zahlreiche Spekulationen 
den Text zwischen Ende November 1923 und Ende Januar 1924. ${ }^{466}$ Erschienen ist er erstmals 1928 in der Zeitschrift Witiko unter dem Titel Der Bau und anschließend in Max Brods 1931 zusammengestelltem Sammelband aus Kafkas Nachlass. ${ }^{467}$

Wie eng Kafkas Architektur mit der Ordnung und den Institutionen zusammenhängt, zeigt Rüdiger Campe in seiner Studie zum Institutionenroman. Er legt dar, wie Architektur und Topografie die Institution und ihre Vertreter auszeichnen. ${ }^{468}$ In Der Bau gibt es eine Reduktion auf das räumliche Moment und dessen Implikationen. Ordnung wird dabei als etwas hochgradig Prekäres dargestellt, das in ihrer Herstellung fortlaufend unterwandert wird. In Kafkas

zum Fortgang des Textes. Dora Diamant, die letzte Partnerin Kafkas, gab laut Max Brod an, der Text hätte in einen Kampf zwischen dem Erzähler und dem anderen Wesen gemündet: „Die Arbeit war vollendet; es fehlt in den erhalten gebliebenen Blättern nicht mehr viel bis zum Schluß gespannter Kampfstellung in unmittelbarer Erwartung des Tieres und des entscheidenden Kampfes, in dem der Held unterliegen wird." Max Brod und Hans-Joachim Schoeps, „Nachwort“, in Franz Kafka. Beim Bau der Chinesischen Mauer. Ungedruckte Erzählungen und Prosa aus dem Nachlaß. Herausgegeben von Max Brod und Hans Joachim Schoeps. Originalgetreuer Nachdruck der Ausgabe Berlin 1931 (Hildesheim, Zürich, New York: Georg Olms Verlag, 2008), 261. Man beachte auch hier die Unentschiedenheit, ob es nun zu einem Kampf kommt oder ob der Erzähler „in Erwartung" des Kampfes verharrt und die Niederlage eine bloße Möglichkeit ist.

Dagegen betont Britta Maché die Wichtigkeit, diese biografischen Informationen miteinzubeziehen. Vgl. Britta Maché, „The Noise in the Burrow. Kafka's Final Dilemma“, The German Quarterly 55, Nr. 4 (1982): 526-540, https://doi.org/10.2307/404637.

466 Kafka, Nachgelassene Schriften und Fragmente II. Appartband, $143 \mathrm{ff}$.

467 Franz Kafka, Beim Bau der Chinesischen Mauer. Ungedruckte Erzählungen und Prosa aus dem Nachlaß. Herausgegeben von Max Brod und Hans Joachim Schoeps. Originalgetreuer Nachdruck der Ausgabe Berlin 1931, hg. von Max Brod und Hans-Joachim Schoeps (Hildesheim, Zürich, New York: Georg Olms Verlag, 2008).

468 „Sie [die Institution] setzt an die Stelle des Wesens des Menschen, das sich nicht selbst genügt, den Kunstbau ihrer Gehäuse und Strukturen.“ Campe, „Kafkas Institutionenroman. Der Proceß, Das Schloß“, 20o. Die Institution ist eng verknüpft mit der Topografie: „Mit der Topographie - der Beobachtung ihres Innen und Außen, dem Verlauf der Grenze und den Regeln des Übertritts - ist man ganz bei der Institution selbst angelangt. In ihrer Topographie manifestiert sich die Institution als sie selbst." Campe, 204.

Den Zusammenhang von Figuren und Institutionen heben auch Simons und Höcker hervor: „Institutionen bedürfen der Vertreter, Grenzwächter, Türhüter, Ratgeber und Sekretäre, um ihre Ordnungen zu entfalten. Gerade diesen Figuren schenkt Kafka seine Aufmerksamkeit. Sie dienen einerseits der Institutionenbildung, andererseits scheinen sie diesen Institutionen selber gar nicht anzugehören. [...] Kafkas Texte sind Institutionengeschichten.“ Oliver Simons und Arne Höcker, „Kafkas Institutionen. Einleitung", in Kafkas Institutionen, hg. von Oliver Simons und Arne Höcker (Berlin, Boston: transcript, 2007), 12. 
Bau wird nicht nur auf Kontingenz reagiert, sie wird kontinuierlich selbst erzeugt. ${ }^{469}$

Vierzehnmal taucht das Morphem „Plan“ in der Erzählung auf. Wie der Begriff Bau ist auch Plan vieldeutig und wird in verschiedenen Bedeutungskontexten verwendet. Der Plan ist als Tätigkeit avisiert - der Erzähler plant einen Tunnel zu bauen - sowie als materieller Plan im Sinn einer Karte oder eines Bauplans. Auf der einen Seite meint Plan also eine in die Zukunft gerichtete Handlungsabsicht, auf der anderen eine materielle oder bloß gedachte Beschreibung. Die Begriffe Plan und Bau konnotieren jeweils die Bedeutung von Struktur und Ordnung. Der Bauplan kann auch auf das Bauen des Plans referieren, wie auf den Bau als Text. Mit diesen beiden zentralen Begriffen in Der Bau sind wichtige Eckpunkte der Erzählung abgesteckt. Pläne entwerfen und verwerfen sowie das Bauen sind zentrale Geschäfte des Bau-Bewohners und Erzählers. 470

Im Folgenden wird die Darstellung von Ordnung anhand des Baus und seiner Topografie, zentraler Differenzierungen und der Funktion des Planens

469 Die Ambivalenz der Architektur des Baus hat Friedrich Kittler deutlich herausgestellt. In seiner Lektüre des Bau vertritt er die These, dass der Bau an die Schützengräben des Ersten Weltkriegs gemahnt. Diese Interpretation, die auf einem engen Bezug zu Kafka als Person beruht, widerspricht der hier vertretenen, eher auf das Formale ausgerichteten Interpretation nicht. Kittlers inhaltliche Konkretion zeigt vielmehr, welche Ordnung sich im Text manifestiert: die Ambivalenz zwischen Leben und Tod, Freund und Feind sowie eine architekturale Ordnung des Grabens, welche auch als Schreibmetapher wirksam ist. Vgl. Wolf Kittler, „Grabenkrieg - Nervenkrieg - Medienkrieg. Franz Kafka und der 1. Weltkrieg“, in Armaturen der Sinne. Literarische und technische Medien 1870 bis 1920, hg. von Jochen Hörisch und Michael Wetzel (München: Wilhelm Fink, 1990), 289-309.

470 Vgl. dazu auch die Interpretation des Baus als Metapher für den Schreibvorgang selbst: „It is compelling to think that Kafka has coded in the metaphor of the burrow his ,house of art' - an imaginary lodging for his being-a-writer (Schriftstellersein). The connection is strengthened by the link between the scratching, digging activity (scharren) of the burrowing creature and the act of writing (schreiben) [...]." Stanley Corngold, Franz Kafka. The Necessity of Form (Cornell: Cornell University Press, 1988), 282. Hervorhebung i. O. Corngold sieht im Bau also gleichsam einen Bau für Kafka selbst, eine Beschreibung von Kafkas Schreiben, mithin eine Metapher für sein Werk selbst.

Vgl. dazu auch Schmitz-Emans: „Als späte große Allegorie über das (Autor-)Ich und die (Schreib-)Arbeit knüpft Der Bau zwar an die Thematik vieler, ja aller vorangegangenen Werke an; sie alle sind in hohem Maße autoreferentiell. Das Thema verdichtet sich hier aber besonders. Schreiben bedeutete einst, Schriftspuren in eine Grundfläche einzugraben; vor allem über das griechische Wort ,graphein' läßt sich eine etymologische Verbindung zwischen ,graben` und ,schreiben herstellen.“ Monika Schmitz-Emans, „Dädalus als Minotaurus. Zu Labyrinth-Motiv und Sprachreflexion bei Kafka und Dürrenmatt“, Zeitschrift für Germanistik 3, Nr. 3 (1993): 528. Vgl. dazu auch Bettine Menke, Prosopopoiia. Stimme und Text bei Brentano, Hoffmann, Kleist und Kafka (München: Wilhelm Fink, 2000). 
untersucht. Auf dieser Basis kommt das Erzählen als Ursprung dieses Raums selbst in den Blick, wobei sich insbesondere die prekäre Zeitordnung herausstellen wird. Die Analysen werfen Licht auf die Problematik des Ereignisses und der Erzählsituation, die zum Schluss in der Performanz aufgeht.

\subsection{Figurationen von Ordnung. Vom Bauen und Planen}

Auf inhaltlicher Ebene wird Ordnung im Text durch die Thematisierung binärer und mehrteiliger Unterscheidungen in den Fokus gerückt. Zahlreiche Merkmale, die im realen kulturellen Bezugsrahmen zentrale Bedeutung für die Beschreibung einer Identität haben, entziehen sich in Der Bau durch ambivalente Bewertung einer Zuordnung. Dies gilt für den Erzähler, den Bau und die Bedeutung des Planens. Auf diese Weise wird die Ordnung in verschiedenen Hinsichten und auf mehreren Ebenen prekarisiert, weil keine verlässlichen Zuschreibungen getroffen werden können.

\subsubsection{Die Architektur des Baus}

Für die Ordnungsfiguration des Bau ist die Architektur zentral. ${ }^{471}$ Bezeichnend ist, dass sich kaum verlässliche Informationen zum Bau finden lassen und er nur punktuell und mit zahlreichen Widersprüchen beschrieben wird. Der Bau verfügt über einen einzigen Zugang, der durch eine mit Moos überwachsene Falltür verborgen ist. ${ }^{472}$ Unter der Falltür entfaltet sich ein Labyrinth, das aus

471 Damit ist natürlich immer auch die Architektur der Sprache gemeint. Schmitz-Emans arbeitet Parallelen zwischen Kafka und Mauthner heraus: „Jeder Sprecher ist durch seine Sprache vereinzelt, und Verständigung ist unmöglich, da es letztlich nur Individualsprachen gibt; die Sprache besteht aus Metaphern, verfehlt zwangsläufig das Wesen der Dinge und führt jeden irre, der sich auf sie verläßt." Schmitz-Emans, „Dädalus als Minotaurus. Zu Labyrinth-Motiv und Sprachreflexion bei Kafka und Dürrenmatt“, 53of.

472 Deleuze und Guattari betonen in ihrer einflussreichen Lektüre Kafkas die selbstreflexive Ebene als eine Befreiung des Signifikanten: „Der Bau in der gleichnamigen Erzählung scheint zwar nur einen Eingang zu haben; allenfalls denkt das Tier an die Möglichkeit eines zweiten, bloß zur Überwachung. Aber das ist eine Falle, aufgestellt vom Tier und von Kafka selbst; die ganze Beschreibung des Baus dient nur zur Täuschung des Feindes. [...] Das Prinzip der vielen Eingänge behindert ja nur das Eindringen des Feindes, des Signifikanten; es verwirrt allenfalls jene, die ein Werk zu ,deuten' versuchen, das in Wahrheit nur experimentell erprobt sein will.“ Deleuze und Guattari, Kafka. Für eine kleine Literatur [franz. 1975], 7 .

Weitere Eingänge werden nicht erwähnt, was jedoch nicht beweist, dass es keine weiteren geben kann. Zu bedenken ist, dass die vielen Schächte des „Kleintiers“ irgendwo Eingänge aufweisen können. Insofern ist die These der vielfachen Eingänge von Gilles Deleuze und Félix Guattari doch nicht so leicht von der Hand zu weisen, wie 
den „Anfangszeiten des Baues“ (B 626) ${ }^{473}$ stammt. Anschließend führt der „erste[] Gang“ (B 598) zum Zentrum, das sich „[n]icht ganz in der Mitte des Baues“ (B 580) befindet, dem „Burgplatz“, einer großräumigen Höhle, in der der Ich-Erzähler seine Vorräte aufbewahrt. Vom Burgplatz gehen zehn weitere Gänge ab, die in einem Abstand von hundert Metern jeweils zu mehr als fünfzig Plätzen führen, an denen das Erzähler-Ich stets alternierend zu schlafen pflegt. Neben diesen Gängen gibt es weitere „Kreuz- und Quergänge“ (B 584).

Diese Beschreibungen scheinen auf den ersten Blick selbsterklärend zu sein, bergen jedoch viele Unklarheiten. Sie wirken, als seien sie wie die Falltür zur Tarnung des eigentlichen Baus angelegt. Es ist beispielsweise nicht klar, ob die „Kreuz- und Quergänge“ (B 584) Verbindungswege zwischen den anderen Hauptgängen oder die Hauptgänge selbst sind. Ungesichert ist auch die Anzahl der Gänge, da der Standpunkt, von dem aus gezählt wird, nicht genannt wird. Es heißt einzig: „Wenn ich auf dem Burgplatz stehe, umgeben von den hohen Fleischvorräten, das Gesicht zugewendet den zehn Gängen, die von hier ausgehn" (B 6oo). Mit der Anbindung der Zählweise an die Körperposition des Erzählers wird unklar, ob jener erste Gang mitgezählt wurde, der vom Eingang herführt, oder ob nur diejenigen gezählt wurden, die vor dem Ich-Erzähler liegen. Jedenfalls wird nicht erwähnt, ob sich vielleicht hinter dem Erzähler noch andere befinden. Es ist gut möglich, dass sich diese Gänge im weiteren Verlauf verästeln oder dass sie in einer Schlaufe wieder zum Burgplatz zurückführen, es sich also um nur fünf weitere Gänge mit je zwei Eingängen handelt. Angesichts der permanenten Veränderungen, Verbesserungen und Wartungsarbeiten, die der Erzähler am Bau vornimmt, ist es naheliegend, dass es

Katrin Dennerlein dies tut. Katrin Dennerlein, „Die Zerstörung des idealen Habitats als unerhörte Begebenheit", in Die Räume der Literatur. Exemplarische Zugänge zu Kafkas Erzählung „Der Bau“, hg. von Dorit Müller und Julia Weber (Berlin, Boston: De Gruyter, 2013), 153-177.

Deleuze und Guattaris Sichtweise wird prominent weitergeführt von Henry Sussman, „The Calculable, the Incalculable, and the Rest. Kafka's Virtual Environment“, MLN 127, Nr. 5 (2012): 1144-1170, https://doi.org/10.1353/mln.2012.0144; Hans H. Hiebel, Franz Kafka. Form und Bedeutung. Formanalysen und Interpretationen von "Vor dem Gesetz", "Das Urteil", „Bericht für eine Akademie“, „Ein Landarzt“, „Der Bau“, „Der Steuermann“, "Prometheus", „Der Verschollene“, „Der Process“ und ausgewählten Aphorismen (Würzburg: Königshausen \& Neumann, 1999); Bettine Menke, Prosopopoiia. Stimme und Text bei Brentano, Hoffmann, Kleist und Kafka. Hiebel hat die These auch auf Robert Walsers Werke übertragen: Hiebel, „Robert Walsers ,Jakob von Gunten‘. Die Zerstörung der Signifikanz im modernen Roman“.

473 Hier und im Folgenden wird mit der Sigle B auf die Kritische Ausgabe verwiesen: Franz Kafka, „Bau'-Konvolut“, in Franz Kafka. Schriften Tagebücher Briefe. Kritische Ausgabe, hg. von Jürgen Born u. a., Bd. Nachgelassene Schriften und Fragmente II, hg. von Jost Schillemeit (Frankfurt am Main: Fischer Verlag, 1992), 575-632. 
auch Gänge gibt, die nicht mehr zugänglich sind, da sie nicht mehr gewartet werden. Des Weiteren sind Forschungsgänge und Probebohrungen, die nicht weiterverfolgt wurden, wahrscheinlich. ${ }^{474}$ Zur Verwirrung trägt bei, dass auch die Nebenplätze immer wieder als Haupt- und Nebenvorratsplätze verwendet werden, die Funktionen der Plätze sich also verändern. Die Ausmaße des Baus lassen sich ungefähr berechnen. Bei fünfzig Plätzen alle hundert Meter ergäbe sich eine Mindestlänge von fünf Kilometern. In den Worten des Erzählers verfügt der Bau jedoch über eine „ungeheure[] Ausdehnung“ (B 577), was auf ein größeres Ausmaß schließen lässt. Die deutlichste Struktur des Baus ist wohl das Labyrinth, das kurz nach dem Eingang folgt, und in der Sekundärliteratur fälschlicherweise immer wieder zur Beschreibung des ganzen Baus verwendet wird. ${ }^{475}$ Der Bau als Ganzes ist jedoch kein Labyrinth. ${ }^{476}$ Struktur und Grenzen sind auffällig vage; es ist naheliegend, dass es keinen verbindlichen Plan zum Bau gibt, wenn der Erzähler auch anderes behauptet. ${ }^{477}$

\subsubsection{Ambivalenz in der Differenzierung}

Im Folgenden werden die explizit ambivalenten Zuschreibungen in Der Bau untersucht. Stetige Grenzziehungen und deren Auflösungen spiegeln explizite

474 Die Bauanlage ist nicht so eindeutig, wie Heinrich Henel sie beschreibt. Heinrich Henel, „Das Ende von Kafkas ,Der Bau““, Germanisch-Romanische Monatsschrift 22 (1972): 5.

475 Vgl. Roger Thiel, Anarchitektur. Lektüren zur Architektur-Kritik bei Franz Kafka (Berlin: Vorwerk 8, 2011); Vivian Liska, „Der Bau“', in Franz Kafka-Handbuch. Leben - Werk Wirkung, hg. von Manfred Engel und Bernd Auerochs (Stuttgart: Metzler, 2010), 337-343; Jörg Gallus, Labyrinthe der Prosa. Interpretationen zu Robert Walsers "Jakob von Gunten", Franz Kafkas „Der Bau“ und zu Texten aus Walter Benjamins „Berliner Kindheit um neunzehnhundert", Literatur als Sprache (Frankfurt am Main, Berlin, Boston, u. a.: Peter Lang, 2006). Explizit dagegen argumentiert Dennerlein, „Die Zerstörung des idealen Habitats als unerhörte Begebenheit".

476 So sehr sich die Struktur des Labyrinths für die Beschreibung des Baus anbieten würde, so wenig ist sie stimmig - wenn das Labyrinth in den 1920er-Jahren auch durchaus ein wichtiger Topos in der Literatur war. Vgl. Utz, Tanz auf den Rändern, 369-422. Das Labyrinth dient Gallus als Chiffre für einen Vergleich zwischen Kafka und Walser: Gallus, Labyrinthe der Prosa.

Ob die Struktur des Baus einem Rhizom entspricht, wie Deleuze und Guattari dies behaupten, muss offenbleiben. Es gibt Indizien, die auf eine offene, sich verändernde Struktur hinweisen, wie es auch Argumente für eine eher geschlossene Struktur gibt. Vgl. Deleuze und Guattari, Kafka. Für eine kleine Literatur [franz. 1975]. Dennerlein sieht insbesondere im Umstand, dass der Bau über ein Zentrum verfügt, den Grund, warum ein Vergleich mit dem Rhizom keinen Sinn macht. Dennerlein, „Die Zerstörung des idealen Habitats als unerhörte Begebenheit“, 159. Die Bedeutung des Eingangslabyrinths als „[k]ein klassisches Labyrinth“ betont Schmitz-Emans, „Dädalus als Minotaurus. Zu Labyrinth-Motiv und Sprachreflexion bei Kafka und Dürrenmatt", 528 .

Siehe Kap. 4.1.4 Der „Gesamtplan“. Aporetische Genese des Baus, S. 22off. unten. 
ambivalente Zuschreibungen, welche in Bezug auf die Benennung und Zweckbestimmung des Baus, die Differenzen zwischen Innen und Außen, Ich und dem Anderen bis hin zu der Frage, welcher biologischen Art das Erzähler-Ich zugerechnet werden kann, analysiert werden können. ${ }^{478}$

\section{Rettungsloch oder Burg}

Zur Beschreibung des Baus werden mit ganz unterschiedlichen Konnotationen versehene Worte verwendet: „Höhlung“ (B 599), „Loch“ (B 6oo) und „nicht nur ein Rettungsloch“ (B 60o), „Burg“ (B 601) und „alte[] Wohnung“ (B 603).479 Rund zwanzigmal wird er als Haus bezeichnet. ${ }^{480}$ Mit siebzig Nennungen ist die Bezeichnung Bau deutlich am meisten vertreten, die jedoch ihrerseits wieder vieldeutig ist. Das Wörterbuch der Gebrüder Grimm unterscheidet zehn

478 Vgl. Wegmann: „Der Bau is characterized by various levels at which the dissolution of boundaries takes place - dissolutions that also affect habitation and dwelling-place, these serving to distinguish protected from unprotected space, Drinnen from Draussen." Thomas Wegmann, „The Human as Resident Animal. Kafka's ,Der Bau' in the Context of His Later Notebooks and Letters“, Monatshefte 103, Nr. 3 (2011): 368. Hervorhebung i. O.

479 Mag die Bezeichnung "Wohnung“ auf den ersten Blick befremdlich wirken, lässt sie der Blick auf Brehms Tierleben verständlich erscheinen, wo der Bau des Dachses als "Wohnung" bezeichnet wird. Alfred Brehm, Brehms Tierleben. Allgemeine Kunde des Tierreichs. Mit 1800 Abbildungen im Text, 9 Karten und 180 Tafeln in Farbdruck und Holzschnitt, dritte, gänzlich neubearbeitete Auflage von Eduard Pechuel-Loesche, Bd. Säugetiere Erster Band (Leipzig, Wien: Bibliographisches Institut, 189o), 646.

48 o Auch diese ambivalente Bedeutungszuschreibung von Haus mag psychoanalytischen Lektüren, die sich auf Freuds Gebrauch der Haus-Metapher stützen konnten, Auftrieb geben. Was Freud in Eine Schwierigkeit der Psychoanalyse schreibt, erstaunt durch die große Nähe zum Bewohner des Baus: „In gewissen Krankheiten, allerdings gerade bei den von uns studierten Neurosen, ist es anders. Das Ich fühlt sich unbehaglich, es stößt auf Grenzen seiner Macht in seinem eigenen Haus, der Seele. Es tauchen plötzlich Gedanken auf, von denen man nicht weiß, woher sie kommen; man kann auch nichts dazu tun, sie zu vertreiben. Diese fremden Gäste scheinen selbst mächtiger zu sein als die dem Ich unterworfenen; sie widerstehen allen sonst so erprobten Machtmitteln des Willens, bleiben unbeirrt durch die logische Widerlegung, unangetastet durch die Gegenaussage der Realität. Oder es kommen Impulse, die wie die eines Fremden sind, so daß das Ich sie verleugnet, aber es muß sich doch vor ihnen fürchten und Vorsichtsmaßnahmen gegen sie treffen. Das Ich sagt sich, das ist eine Krankheit, eine fremde Invasion, es verschärft seine Wachsamkeit, aber es kann nicht verstehen, warum es sich in so seltsamer Weise gelähmt fühlt.“ Sigmund Freud, „Eine Schwierigkeit der Psychoanalyse“, in Gesammelte Werke. Chronologisch geordnet, hg. von Anna Freud, Bd. 12: Werke aus den Jahren 1917-1920 (Frankfurt am Main: Fischer, 1966), 9.

Vgl. auch Snyder: ,The burrow is a hidden kingdom, and the narrator is its dynastic ruler, although pathetically, a ruler without subjects, servants or even witness." Verne P. Snyder, „Kafka's ,Burrow'. A Speculative Analysis“, Twentieth Century Literature 27, Nr. 2 (1981): 115, https://doi.org/10.2307/441134. 
Bedeutungen, von denen folgende für die Zwecke dieser Studie interessant sind: „wohnung“ für die „wilden thiere[]“, „behausung und wohnstätte der menschen“, „errichtung des hauses“, „structura, constructio“, aber auch „gefängnis“ und „festungsbau“, in den „der missethäter kommt“.481

Die Benennungen des Baus schwanken sowohl in der Art und Weise der Behausung und ihrer konnotierten (Un-)Gemütlichkeit, wie sie auch unterschiedliche Urteile bezüglich der Qualität und erforderlichen Baukenntnisse implizieren. ${ }^{482}$ Bedarf es für ein bloßes „Loch“ keiner Meisterschaft, so setzt eine „Burg“ doch große Anforderungen an Statik; wo der eine Begriff tiefstapelt, ist der andere eine Übertreibung. Dies zieht eine tiefgreifende Verunsicherung der Semantik nach sich. ${ }^{483}$

\section{Freiheit oder Gefangenschaft}

Mit den Bezeichnungen des Baus stellt sich auch die Frage nach dessen Funktion. Laut dem Erzähler-Ich soll der Bau ein Ort der Stille und Sicherheit sein. Zentral ist die Idee eines Versteckes, das gleichzeitig ein Verteidigungsbau sein soll. Diese zwei Sicherheitsaspekte vertragen sich schlecht, wie am Loch als Versteck und der Burg als sichtbarem Bollwerk ersichtlich ist.

Eine weitere Bedeutung steht ebenfalls prominent im Raum, die vom Erzähler jedoch nicht explizit erwähnt wird: der Bau als Gefängnis. Die Frage, wie frei das Erzähler-Ich in seinem Bau tatsächlich ist, ist untergründig stets präsent. ${ }^{484}$ Zwar vermeidet es der Erzähler tunlichst, ein schlechtes Licht auf den Bau zu werfen. Dennoch gibt es deutliche Argumente dafür, den Aufenthalt im Bau als eine Art von Gefangenschaft und den Bau selbst als Gefängnis zu verstehen. Indiz dafür sind die Freude und der plötzliche Tatendrang, die das Erzähler-Ich jeweils ergreifen, wenn es den Bau verlässt. Das Ich fühlt „in [s]einem Körper neue Kräfte, für die im Baue gewissermaßen kein Raum

481 Grimm und Grimm, „Bau“.

482 In einer gestrichenen Stelle attribuiert der Erzähler seiner Herkunft „[e]twas Baumeistermässiges“. Kafka, Nachgelassene Schriften und Fragmente II. Appartband, 429.

483 Im Vergleich mit Theodor Fontanes Polysemantik des Stechlin wird hier der entgegengesetzte Weg beschritten. Ist es beim Stechlin ein Begriff, der sich auf mehrere, zwar verbundene, aber doch deutlich getrennte Elemente bezieht, so handelt es sich beim Bau um ein Signifikat, das mit unterschiedlichen Namen bedacht wird, die einzig über die abstrakte Funktion „Behausung“ verknüpft sind. Insbesondere die widersprüchlichen emotionalen Färbungen fallen auf.

484 Vgl. dazu Vivian Liska: „Der Bau, der ursprünglich als Ort der Sicherheit, Gewissheit und Geborgenheit angesehen wurde, wandelt sich in die existenzielle Bedrohung um, gegen die er ursprünglich als Schutz konzipiert worden war. Er lässt sich dementsprechend zugleich als Schutzgraben und Gefängnis verstehen, wodurch das Tier-Ich prinzipiell zu keinem einzigen Handlungsentschluss gelangen kann.“ Liska, „Der Bau““, 338. 
ist“ (B 590), auch die Ernährung ist „draußen eine bessere, die Jagd zwar schwieriger, der Erfolg seltener, aber das Ergebnis in jeder Hinsicht höher zu bewerten“ (B 590). Draußen ergreift das Erzähler-Ich „manchmal de[r] kindische[] Wunsch [...] überhaupt nicht mehr in den Bau zurückzukehren“ (B 592). In dieser Hinsicht ist der Bau weit davon entfernt, ein „ideales Habitat“ zu sein. ${ }^{485}$

Diese implizite Kritik am Bau, die in der Wertschätzung der Außenwelt liegt, relativiert der Erzähler sofort. Er könne die Ausflüge nur genießen, weil er dieser anstrengenderen und ungeschützteren Lebensart nicht dauerhaft ausgesetzt sei. Nur im Wissen darum, dass er nicht immer draußen jagen müsse, sondern „daß meine Zeit gemessen ist, daß ich nicht endlos hier jagen muß sondern daß mich, gewissermaßen wenn ich will und des Lebens hier müde bin, jemand zu sich rufen wird, dessen Einladung ich nicht werde widerstehen können.“ (B 590) Nur so kann er die Zeit draußen "ganz auskosten und sorgenlos verbringen" (B 590).

Diese Argumentation des Erzählers macht insofern Sinn, als die Freiheit nur dann ein Genuss ist, wenn sie freiwillig ist und die Sicherheit des Bekannten verfügbar bleibt. Es stellt sich jedoch heraus, dass die dauernde Sorge um den Bau den Erzähler daran hindert, die Freiheit draußen zu genießen: „Zuviel beschäftigt mich der Bau." (B 59o) Er bleibt dem Bau so sehr verpflichtet, dass er sich gar nicht wie im Freien fühlt: „Aber im Freien bin ich eigentlich nicht“ (B 59o). Entsprechend versteckt er sich und belauert den Eingang seines Baus. In diesem Doublebind ist der Bewohner und Erzähler des Baus an diesen gefesselt.

Innen und Außen. Der paradoxe Lieblingsplan

Die Differenz zwischen Innen und Außen, Freiheit und Gefangenschaft überführen grundsätzliche Ordnungskriterien in eine unauflösliche Ambivalenz. ${ }^{486}$

485 Katrin Dennerlein findet entsprechend: „Den Bau als Gefängnis zu bezeichnen, ist meiner Meinung nach ebenfalls schwierig, weil erstens das Freie nicht der Lebensraum des Tieres ist, da es sich um ein grabendes Tier handelt, und es sich zweitens nicht eingesperrt, sondern zu Hause fühlt.“ Dennerlein, „Die Zerstörung des idealen Habitats als unerhörte Begebenheit“, 164. Damit scheint Dennerlein jedoch einerseits zu sehr davon auszugehen, dass es sich um ein maulwurfähnliches Tier handelt - was keineswegs sicher ist -, und andererseits die ambivalente Dynamik zwischen Sicherheit und Gefangenschaft zu übersehen, die Der Bau deutlich grundiert. Auch übersieht sie, dass das Erzähler-Ich früher durchaus über der Erde gelebt hat.

486 „Meine Gefängniszelle - meine Festung“ notiert Kafka Ende Februar 1920 in sein Tagebuch und nimmt so dieses Doublebind von Gefangenschaft und Sicherheit vorweg. Franz Kafka, Tagebücher, in Franz Kafka. Schriften Tagebücher Briefe. Kritische Ausgabe, 
Scheint es beispielsweise zunächst so, als ob erst der Bau den Genuss der Freiheit ermöglicht, stellt sich heraus, dass es gerade der Bau ist, der diesen verhindert. Das Doublebind zwischen Innen und Außen bzw. Freiheit und Gefangenschaft wird als Prozess modelliert und bewegt sich von einer Position zur anderen. Gewissheit oder Erkenntnis sind in dieser Anlage nicht möglich. ${ }^{487}$

Dieses Dilemma projiziert der Erzähler in den Bau. Einer seiner "Lieblingspläne“ (B 611) ist es, einen Schutzraum um den Burgplatz zu bauen, so dass er sich gleichzeitig innerhalb und außerhalb des Burgplatzes aufhalten kann. In diesem Paradox liegt für den Erzähler die ideale Lösung des Problems. ${ }^{488}$ Im Wunsch, die Differenz zwischen Innen und Außen zu überwinden, wird die Ambivalenz in Bezug auf die Unterscheidung von Innen und Außen umso deutlicher. Der unmögliche Aufenthalt in dieser Schutzkammer der Aporie scheint dem Erzähler als sicherster Ort.

\section{Ich und das Andere}

Schließlich wird im Text mit der Opposition von Innen und Außen auch die grundlegende Differenz zwischen dem Ich und dem Anderen aufgegriffen. So scheinen das Erzähler-Ich und der Bau an manchen Stellen zu verschmelzen:489 „[I]ch und der Bau gehören so zusammen [...], denn nichts kann uns auf die Dauer trennen“ (B 6o2). Die „lange Wanderung durch die Gänge“ nach der Rückkehr vom Ausflug ist ein „Plaudern mit Freunden“ (B 604). Die Gänge nehmen in der Wahrnehmung des Ich die Gestalt von Subjekten an:

hg. von Jürgen Born u. a., Bd. hg. von Hans-Gerd Koch, Michael Müller und Malcolm Pasley (Frankfurt am Main: Fischer, 2002), 859. Vgl. dazu und zum „Zirkel von Innen und Außen“: Hiebel, Franz Kafka, 29-32. Hiebel stellt sogar die Möglichkeit in den Raum, dass jener Aphorismus über die Gefängniszelle „[e]iner der Ursprünge“ des Bau gewesen sein könnte. Hiebel, 26.

487 Der Erzähler hat zwar Erkenntnisse, diese werden jedoch, wie zu sehen sein wird, durch iterative Erzählweise ad absurdum geführt. Siehe Kap. 4.2.1 Zur „Trunkenheit der Iteration“. Paradoxie der Zeitordnung, S. 225ff. unten.

488 Von einer bautechnischen Seite her gesehen wäre es möglich, einen solchen Zwischenraum zu konstruieren, jedoch wäre das wohl nicht im Sinn des Erzählers, da dieser Raum bloß einen weiteren Gang darstellen würde. Was ihm vorschwebt, ist ein in sich abgeschlossener Raum um den Burgplatz herum, also eine Art von idealistischmetaphysischer Fantasie, die eigentlich unmöglich ist. Vgl. zum Ideal des Paradoxes in Der Bau auch die Beschreibung, dass der perfekte Bau "gleichzeitig warm und kühl“ (B 579) ist.

489 Driscoll versteht den Bau als „extension of his own body“. Kári Driscoll, „Toward a Poetics of Animality. Hofmannsthal, Rilke, Pirandello, Kafka“ (Diss, New York City, Columbia University, 2014), 171 . 
Euretwegen Ihr Gänge und Plätze, und Du vor allem Burgplatz, bin ich ja gekommen, habe mein Leben für nichts geachtet nachdem ich lange Zeit die Dummheit hatte seinetwegen zu zittern und die Rückkehr zu Euch zu verzögern. Was kümmert mich die Gefahr jetzt, da ich bei Euch bin. Ihr gehört zu mir, ich zu Euch, verbunden sind wir, was kann uns geschehn. [...] Und mit seiner Stummheit und Leere begrüßt nun auch mich der Bau und bekräftigt was ich sage. (B 6o5)

Als das Zischen einsetzt, das den Erzähler aus dem Schlaf weckt, ist nicht klar, um was es sich dabei handelt. Ist es ein fremdes Wesen, sind es mehrere, ist es ein Geräusch, das aus den Lüftungsschächten herrührt oder doch vom Erzähler selbst stammt?490 Ebenso ist es fraglich, wie dieses Wesen dem Erzähler gesinnt wäre. Die Möglichkeit, dass es sich beim „Zischer“ nicht um einen Feind handelt, verwirft der Ich-Erzähler, obwohl es sich durchaus um einen Artgenossen handeln könnte. Für ihn ist klar, dass „Verständigung“ nicht möglich wäre (B 630). Ein besinnungsloser Kampf erscheint ihm ausweglos. ${ }^{491}$ Diese Einschätzung der Situation ist der paranoiden Wahrnehmung des Erzähler-Ich geschuldet, das jede Veränderung der Situation als Bedrohung sieht. Das oben beschriebene Doublebind ist auch hier aktiv. Dem Ich-Erzähler geht es darum, den Bau zu verteidigen. Dies wird er notfalls gegen sich selbst tun müssen, ist es doch möglich, dass das Zischen von ihm selbst herrührt, dass also der „Zischer“ eigentlich der Erzähler selbst ist.

Es zeigt sich, dass in Der Bau Differenzen, die für den kulturellen Bezugsrahmen der Moderne konstitutiv sind, wie Innen/Außen, Ich/Andere, Freiheit/ Gefangenschaft, in die Unbestimmtheit führen sowie die Topografie des Baus sich als widersprüchlich herausstellt. Wenn auch der Erzähler unverkennbar einer Kriegs- und Verfolgungsordnung verfallen ist, macht der Text doch deutlich, dass diese kontingent und durch den Erzähler selbst hergestellt wird.

490 Um was es sich bei dem Geräusch handelt, ist ein zentraler Punkt in der Forschung zum Bau. Laut Henels existentialistischer Deutung verkörpert das Wesen die Angst, die darin besteht, sich nicht ganz dem Bau zu überlassen, „die das Tier vor seinem Dasein in der Einsamkeit, Leere und Öde des Baus empfindet.“ Henel, „Das Ende von Kafkas ,Der Bau““, 7. Die „unbekannte Schuld ist die mangelnde Hingabe“ an den Bau. Henel, 11. Es ist eine „Metapher für die Todesursache des Tieres“. Henel, 17. Der „Gegner [existiert] nur in der Vorstellung des Tieres“. Henel, 17. Für weitere Positionen, was der Zischer und das Zischen bedeuten, siehe $\mathrm{FN} 538$, S. 236 f. unten.

491 Das ganze Zitat lautet: „In meinem Erdhaufen kann ich natürlich von allem träumen, auch von Verständigung, trotzdem ich genau weiß, daß es etwas derartiges nicht gibt und daß wir in dem Augenblick, wenn wir einander sehn, ja wenn wir einander nur in der Nähe ahnen, gleich besinnungslos, keiner früher keiner später, mit einem neuen andern Hunger, auch wenn wir sonst völlig satt sind, Krallen und Zähne gegeneinander auftun werden." (B 630f.) 
Dadurch, dass der Leser durch die Fokalisierung auf die Stimme und Sicht des Erzählers angewiesen ist, wird die Macht der Erzählform und ihrer Episteme greifbar.

\section{Hände, Scharrpfoten, Barthaare}

Die Unbestimmtheit der Spezies des Erzählers rückt eine weitere Ordnungskategorie ins Zentrum der Aufmerksamkeit. In der Regel wird in der Sekundärliteratur der Erzähler als dachs- und maulwurfähnliches Tier beschrieben. ${ }^{492}$ Diese Kategorisierung ist jedoch keineswegs eindeutig, wie im Folgenden gezeigt wird. Für die hier vorgeschlagene Lektüre, die die Herstellung und Unterwanderung von Ordnung mit Mitteln der Narration ins Zentrum stellt, ist die Ambivalenz zwischen Tier und Mensch von großem Interesse.

In der Beschreibung des Protagonisten finden sich Hinweise, die auf ein Tier hindeuten, aber auch solche, die auf einen Menschen zutreffen: Der Körper des Erzähler-Ich verfügt über ein Fell (B 588), Krallen (B 611), „Scharrpfoten“" (B 621) und eindrückliche Zähne. Wie erwähnt, referieren einzelne Beschreibungen des Verhaltens des Erzählers auf den Dachs und den Maulwurf in Brehms Tierleben. Jedoch hat der Erzähler auch Barthaare (B 589) und nicht Tasthaare, wie dies bei den besagten Tieren heißen müsste. Sodann spricht der Erzähler einmal von einem „von meinen Händen geschaffenen [...] Mangel“ (B 588), wobei die Hand etwas genuin Menschliches ist. Eindrücklich ist neben der Reflexionsfähigkeit und Sprachbefähigung des Erzählers dessen Zeit- und Todesbewusstsein, Eigenschaften, die bei fast allen Tiergestalten Kafkas vorkommen. Ein starkes Indiz für einen Menschen besteht auch darin, dass der Erzähler beständig von anderen Tieren spricht - vom Tier zu sprechen macht jedoch nur für einen Menschen Sinn, der sich in deutlicher Differenz zum Tier sieht. Schließlich heißt es an einer Stelle über den Feind des Erzählers, dieser verfüge über einen „Hinterer“ (B 596), also ein Gesäß, wiederum ein

492 Auch wenn Kafka Beschreibungen des Dachses und des Maulwurfs aus Brehms Tierleben miteinander vermischt und in die Merkmale des Ich-Erzählers einfließen lässt, ist dies noch kein Beweis dafür, dass es sich tatsächlich um ein Tier handeln muss. Als erster hat Binder den Bezug zu Brehms Tierleben aufgedeckt: Hartmut Binder, Kafka-Kommentar zu sämtlichen Erzählungen, 3. Aufl. (München: Winkler Verlag, 1982), 303f., $311 f$.

Vgl. zum Tier bei Kafka: Harald Neumeyer und Wilko Steffens, Hrsg., Kafkas Tiere, Forschungen der Deutschen Kafka-Gesellschaft 4 (Würzburg: Königshausen \& Neumann, 2015).

Zu bemerken ist auch, dass das Wesen über kein Geschlecht zu verfügen scheint. Fortpflanzung spielt keine Rolle. Überhaupt werden sogenannte „tierische“ Instinkte zum Überleben, wie Fressen als Nahrungsaufnahme, nicht im Aktiv beschrieben. 
Ausdruck, der sich auf die Spezies Mensch bezieht, gelesen wird. ${ }^{493}$ Weiter gibt es mehrere Bemerkungen zu sozialen Rollen und Positionen: Einmal ist vom „[a]rme[n] Wanderer, ohne Haus, auf Landstraßen, in Wäldern“ (B 580) die Rede, dann von einem "Landstreicher" (B 590). Gegen diese Figuren grenzt sich der Erzähler ab. Auch der Begriff des „Stampfhammers“ (B 585), mit dem der Erzähler seine Stirn bezeichnet, wird mit dem Werkzeug Hammer zu einem menschlichen Artefakt. Die Nahrung des Erzählers schließlich erscheint ebenfalls menschlich: Das Wesen isst gern „ein schönes Stück enthäutete[s] rote[s] Fleisch[]“ (B 630), das eine Bearbeitung einschließt.

Die Speziesfrage lässt sich nicht eindeutig lösen. ${ }^{494}$ Vielmehr werden permanent Signale in beide Richtungen gesendet, die diese Unbestimmtheit aktuell halten. Dieser Aspekt kommt in der Sekundärliteratur häufig nur am Rande zur Sprache. Das dürfte auch damit zusammenhängen, dass Der Bau wiederholt als ,Tiergeschichte verstanden und neben Erzählungen gestellt wurde, in denen die Spezies deutlich benannt werden kann: Hunde, Affen und Mäuse. ${ }^{495}$ In diesem Zusammenhang wird auch auf Kafkas Der Dorfschullehrer (verfasst um 1914/1915) verwiesen, der von Max Brod unter dem Titel Der Riesenmaulwurf in seinen Erzählungen aus dem Nachlass 1931 herausgegeben wurde. Auch der kulturhistorische Kontext ist zu beachten, wurde doch die Grenze zwischen Mensch und Tier durch die Thesen von Charles Darwin und Jakob Johann von Uexküll aufgeweicht. Die Literatur griff diesen Diskurs auf: 1909 erschien die deutsche Übersetzung einer Erzählung des dänischen Autors Johannes Vilhelm Jensen unter dem Titel Der Kondignog. Darin verwandelt sich ein Mensch in ein echsenähnliches Wesen mit Superkräften als Ausdruck seiner Einsamkeit. ${ }^{496}$

493 Diese Stelle spielt bei Hans Hiebels Lektüre des „Zwangsverhalten[s]“, das „motiviert durch aggressive Sexualabwehr" sei, eine wesentliche Rolle. Insbesondere die Vorstellung des Erzählers, Tiere könnten in den Bau eindringen, hat durchaus eine (gewalt-)sexuelle Konnotation. Vgl. Hiebel, Franz Kafka, 28. Hervorhebung i. O.

494 Ein "hybrid of man and animal“ nennt ihn Hermann J. Weigand, „Franz Kafka's ,The Burrow' (,Der Bau'). An Analytical Essay“, PMLA 87, Nr. 2 (1972): 152, https://doi. org/10.2307/460873. Vgl. auch Snyder: „[H]e is a hybrid of rational Man and instinctive animal“. Snyder, „Kafka's ,Burrow“, 113. Snyder versucht den Bau auf Basis psychoanalytische Konzepte als ,a grotesque satire of the excesses of modern psychology“ zu lesen. Snyder, 115 .

495 Vgl. etwa bei Oliver Jahraus und Bettina von Jagow, „Kafkas Tier- und Künstlergeschichten“, in Kafka-Handbuch. Leben - Werk - Wirkung, hg. von Bettina von Jagow und Oliver Jahraus (Göttingen: Vandenhoeck \& Ruprecht, 2008), 530-552.

496 Die Verwandlung des Protagonisten in das Fabelwesen Kondignog ist, so suggeriert es der Text, Ausdruck von Armut und Einsamkeit. Niemand nimmt seine Verwandlung wahr; wenn er aber erkannt würde, wäre er erlöst. Dies tut Consuelo am Ende, ein Mädchen, ebenso arm und hungernd wie der Protagonist und Erzähler. Interessant an der Erzählung 
Interessanterweise finden sich im Manuskript des ,Bau'-Konvoluts gestrichene Stellen mit weiteren Informationen über die Spezies des Erzählers und deren Verhalten. Es wird geklärt, dass das Wesen früher in Rudeln oder Verbünden an der Erdoberfläche lebte. Es soll weitere seiner Art geben, die nicht alle in einem Bau wohnen. Auch wird deutlich, dass das Wesen verschiedene Stadien der Sozialisierung durchläuft sowie über Talent, unterschiedlich entwickelte Anlagen und Berufungen verfügt. Folgenden Abschnitt hat Kafka als Ganzes gestrichen:

Etwas Baumeistermässiges muss aber immer in meinem Blut gewesen sein, schon als Kind zeichnete ich Zick-zack- und Labyrinthpläne in den Sand und eilte im Geiste auf weichen Pfoten über die sehönen stillen vege vielen Striche hin. Und überall suchte ich einen passenden Ort für den Bau und nirgends konnte ich ihn finden, nirgends passte der Ort zum Plan, kein Ort schien würdig, den Plan aufzunehmen und kein Plan schien stark genug sich einem Ort einzudrücken. Alles war atussichtslos. Ohne Schutz, bestenfalls in Höhlen oder unter trockenen Blättern oder im Rudel meiner Genossen verkrochen ruhte ich,ohne Sehutz in dieser Welt und drückte mich wohl im Schlaf sehnsüchtig an meinen Nachbar, als sei er denn ich hielt ihn für die Wand der Gänge meines Baues. ${ }^{497}$

Es ist bemerkenswert, dass Kafka offensichtlich darum bemüht war, Ambivalenzen zuzuspitzen, statt sie aufzulösen. ${ }^{498}$ So wenig es gesichert ist, dass es sich um ein maulwurfähnliches Tier handelt, so wenig beweist diese Stelle, dass es sich beim Erzähler um eine Art degenerierten Menschen handelt, dessen Körper sich - beispielsweise - anderen, apokalyptischen Lebensbedingungen angepasst hat. ${ }^{499}$ Die Differenz zwischen Mensch und Tier als

ist auch die Zeitstruktur der Erzählung. Nach vollzogener Verwandlung fühlt sich der Protagonist aus der Zeit gefallen, was mit dem Wechsel in die präsentische iterative Erzählweise formal dargestellt wird; erst am Schluss, mit der Erlösung durch die Liebe, kehrt die Erzählung in den Singulativ zurück. Vgl. Johannes V. Jensen, „Der Kondignog“, in Dolores und andere Novellen, Fischers Bibliothek zeitgenössischer Romane (Berlin: Fischer, 1914), 6o-7o.

497 Kafka, Nachgelassene Schriften und Fragmente II. Appartband, 429 f. Das ganze Zitat wurde von Kafka gestrichen; die Streichungen innerhalb sind noch einmal gestrichen worden. Einfügungen oder Überschreibungen werden hier nicht gesondert gekennzeichnet.

498 Diese Streichung von Referenzen zur Zuspitzung von Unbestimmtheit ist ein Verfahren, das Robert Walser ebenfalls angewandt hat. In den späten Berner Jahren hat er Referenzen bis zur Unkenntlichkeit verfremdet, so dass ihre Genese ohne Vorlage nicht mehr nachvollziehbar ist. Vgl. Christian Walt, „Poetik der Anspielung. Zu einem nanotextuellen Element in den Texten Robert Walsers", in Nanotextualität. Ästhetik und Ethik minimalistischer Formen, hg. von Franz Fromholzer, Mathias Mayer und Julian Werlitz, Ethik - Text - Kultur 13 (Paderborn: Wilhelm Fink, 2017), 207-223.

499 An dieser Stelle sei auf die biologische Lehre von Darwins Gegenspieler Jean-Baptiste de Lamarck hingewiesen, dessen Evolutionstheorie auf der Anpassung an die Umwelt 
basales kulturelles Ordnungskriterium wird in Der Bau dauernd provoziert und herausgefordert. ${ }^{500}$ Diese Herausforderung wird durch ein Wesen erzeugt, das sich konstitutiv in der ambivalenten Grenzzone zwischen Mensch und Tier bewegt. 501

\subsubsection{Der panische Plan und die geplante Panik}

Planung und Planbarkeit sind Indizien einer funktionierenden Ordnung. ${ }^{502}$ Der Plan im Sinn einer wohlüberlegten Handlungsabsicht ist ein ordnendes Instrument und gleichzeitig auf eine schon vorhandene Ordnung angewiesen. Der Erzähler betont die Bedeutung des Planens: So gibt es einen "Gesamtplan“ des Baus, es gibt Jagd- und Jahrespläne sowie kleinere Planungen. Dennoch scheint es sich dabei häufig um eine wenig zielführende Tätigkeit zu handeln, die in der sturen Durchführung eines kontingenten Denkmusters besteht. Im Folgenden stechen insbesondere die Leerläufe der Planung ins Auge. Dabei wird deutlich, dass die Inszenierung und Rechtfertigung der Planbarkeit und des planvollen Handelns vielfach subvertiert und aufgehoben wird. Dies geht so weit, dass der Protagonist darauf angewiesen ist, seine eigenen Planungsund Denkprozesse zu unterbinden, um wörtlich in der Panik handlungsfähig zu werden.

\section{Langfristige Planung und spontane Neuordnungen}

Der Protagonist inszeniert sich als ein planendes und entsprechend ordentliches Wesen. ${ }^{503}$ Er legt Vorräte an und hat stets einen "genauen Überblick

beruhte. Auch andere Tierfiguren Kafkas, wie der Affe Rotpeter, zeichnen sich durch herausragende Fähigkeiten zur Adaption an die äußeren Gegebenheiten aus.

500 In Die Verwandlung wird der Übergang vom Menschen zum Käfer ebenfalls ausgesprochen vieldeutig gestaltet, so dass die Grenze zwischen den Spezies nicht genau bestimmbar ist.

501 Auch bei Robert Walser gibt es zahlreiche Tiergeschichten. In diesen geht es weniger um eine Konzentration unvereinbarer Differenzen, deren Aporie narrativ ausgestaltet wird, als um syntaktisch aneinandergefügte Variationen. Vgl. für einen Überblick zu Walsers Tiergeschichten die Anthologie: Robert Walser, Der kleine Tierpark, hg. von Lucas Marco Gisi und Reto Sorg (Berlin: Suhrkamp, 2014).

$5 \mathrm{O} 2$ Vgl. Zygmunt Bauman, dessen Dialektik von Ordnung und Ambivalenz in der Einleitung erörtert wurde: „Mit anderen Worten, klassifizieren heißt, der Welt eine Struktur zu geben: ihre Wahrscheinlichkeiten zu beeinflussen; einige Ereignisse wahrscheinlicher zu machen als andere; sich so zu verhalten, als wären Ereignisse nicht zufällig, oder die Zufälligkeit von Ereignissen einzuschränken oder zu eliminieren." Bauman, Moderne und Ambivalenz, 14. Hervorhebung i. O. Siehe Kap. 1.2.1 Ordnung und Ambivalenz (Bauman), S. 15 ff. oben.

503 Vgl. Dennerlein: „Die Anlage ist durchdacht; das Tier spricht mehrmals von Plänen, die dem Bau zugrunde liegen $(581,582,620)$.“ Dennerlein, „Die Zerstörung des idealen Habitats als unerhörte Begebenheit“, 158. 
über das Vorhandene“ (B 582) auf dem Burgplatz. Auf der Grundlage dieser Übersicht kann er Pläne erstellen: „Ich kann dann auch immer Neuordnungen vornehmen und entsprechend der Jahreszeit die nötigen Vorausberechnungen und Jagdpläne machen." $\left(B_{5} 82\right)^{504}$

In diesen Satz ist eine semantische Spannung eingebaut: Der Erzähler spricht einerseits von langfristiger, den äußeren Umständen angepasster Planung („entsprechend der Jahreszeit“), andererseits von regelmäßigen Änderungen der Pläne („Neuordnungen“). Während Jahrespläne jedes Jahr ähnlich und dauerhaft sind, zeugen die "Neuordnungen“ von spontanen Eingriffen in diese Jahrespläne, stehen mithin in Konflikt zu ihnen. Im weiteren Verlauf der Erzählung erweisen sich diese Neuordnungen als alles andere als planvolle Vorgehen.

Die häufige Beschäftigung mit Verteidigungsvorbereitungen bringt es mit sich, daß meine Ansichten hinsichtlich der Ausnützung des Baues für solche Zwecke sich ändern oder entwickeln, in kleinem Rahmen allerdings. Es scheint mir dann manchmal gefährlich die Verteidigung ganz auf dem Burgplatz zu basieren, die Mannigfaltigkeit des Baues gibt mir doch auch mannigfaltigere Möglichkeiten und es scheint mir der Vorsicht entsprechender die Vorräte ein wenig zu verteilen und auch manche kleine Plätze mit ihnen zu versorgen, dann bestimme ich etwa jeden dritten Platz zum Reservevorratsplatz oder jeden vierten Platz zu einem Haupt- und jeden zweiten zu einem Nebenvorratsplatz udgl. Oder ich schalte manche Wege zu Täuschungszwecken überhaupt aus der Behäufung mit Vorräten aus oder ich wähle ganz sprunghaft, je nach ihrer Lage zum Hauptausgang,

504 Wie nebenbei wird hier die Information vermittelt, dass es auch Jagdpläne gibt, wiewohl eine eigentliche Jagd nie geschildert wird. Der Erzähler rühmt sich, die Gänge von den „Waldmäusen [...] in meinen Bau richtig einzubeziehen, sie bieten mir auch die Möglichkeit weitreichender Witterung und geben mir so Schutz, auch kommt durch sie allerlei kleines Volk zu mir das ich verzehre, so daß ich eine gewisse für einen bescheidenen Lebensunterhalt ausreichende Niederjagd haben kann ohne überhaupt meinen Bau zu verlassen, das ist natürlich sehr wertvoll.“ (B 579) Auf dem Burgplatz lagern jedoch größere Fleischstücke als bloß Mäuse, Ratten und anderes „Kleingetier“. Wenn Jagdpläne bestehen, dann heißt dies auch, dass das Erzähler-Ich diese Ausflüge aus dem Bau nicht etwa zufälligerweise nach dem Umordnen der Vorräte vornimmt, sondern regelrecht als Jagdausflüge plant. Es verwundert, dass das Erzähler-Ich diesen Aspekt nicht herausstreicht, ist es doch sonst sehr darauf bedacht, sich als planvolles Wesen darzustellen.

Vgl. auch die gestrichene Stelle im Manuskript, die etwas mehr Eindeutigkeit gebracht hätte: „[I]ch bin unter anderem zu dem Zwecke ausgezogen Beute Vorräte einzuholen, in der ersten Zeit aber fresse ich alles was ich fange nicht sosehr aus Hunger, als vielmehr im Jägerglück an Ort und Stelle auf." Kafka, Nachgelassene Schriften und Fragmente II. Appartband, 434. Weiter: „Und ich jage nicht nur, um ihn [den Bau] mit neuen Vorräten zu versehn sondern ru zweckvoll und ruhig." Kafka, 434. Da Kafka diese Stellen gestrichen hat, geht es offensichtlich gerade um die Ambivalenz: Das Ziel ist nicht Eindeutigkeit, sondern Verunsicherung. 
nur wenige Plätze. Jeder solche neue Plan verlangt allerdings schwere Lastträgerarbeit, ich muß die neue Berechnung vornehmen und trage dann die Lasten hin und her. (B $5^{82 \mathrm{f} .)}$

Nach der Betonung der Wichtigkeit des Überblicks über die Vorräte folgt überraschend die Beschreibung von verschiedenen Alternativen der Aufbewahrung und Sicherung der Nahrungsmittel. Die Pläne werden in bemerkenswerter Konsequenz und mit Beharrlichkeit vorgetragen. Dabei wird betont, dass jeder dieser unterschiedlichen Aufbewahrungsstrategien ein genauer Plan und entsprechende Berechnungen zugrunde liegen. Jedoch stellt sich die Planhaftigkeit dieser Ordnungen als fragwürdig heraus.

[D]ann habe ich keine Zeit zu Berechnungen, der ich gerade einen neuen ganz genauen Plan ausführen will, fasse willkürlich, was mir unter die Zähne kommt, schleppe, trage, seufze, stöhne, stolpere und nur irgendeine beliebige Veränderung des gegenwärtigen mir so übergefährlich scheinenden Zustandes will mir schon genügen. (B $5^{8} 3$ )

In dieser Beschreibung wird die pure Panik hinter der Umverteilung der Vorräte deutlich. Die Situation soll nicht gesichert werden, einziges Ziel ist es, „,irgendeine beliebige Veränderung“ herbeizuführen.

Die Ursache der Planänderungen und der Panik ist im unbedingten Willen zur Verteidigung des Baus zu finden. Ausschlaggebend für eine Änderung sind jedoch nicht eine Neubewertung der Bedrohungslage oder ähnliche Erkenntnisse des Erzählers. Vielmehr entsteht das Bedürfnis des Erzählers, etwas zu ändern, aus der bloßen „Beschäftigung mit Verteidigungsvorbereitungen“ (B 582). Die Neubewertung der Gefahr ist unmotiviert („Es scheint mir dann manchmal gefährlich“). Es ist also die Tätigkeit des Planens selbst, die die Panik auslöst oder vielmehr mit der Panik zusammenfällt, als Ursache und Ausdruck gleichermaßen.

Später wird deutlich, dass der Erzähler die Umverteilung der Vorräte nicht nur aus Angst vor einem möglichen Feind vornimmt. Die Umverteilung dient auch dazu, die Fressattacken des Protagonisten, „die Selbstbetäubung des besinnungslosen Fressens“, einzudämmen, von denen er immer wieder überwältigt wird, wenn alles Fleisch auf einem Haufen liegt.

Ich suche mich verschiedentlich dagegen zu schützen, die Verteilung auf die kleinen Plätze ist ja auch eine derartige Maßnahme, leider führt sie, wie andere ähnliche Maßnahmen, durch Entbehrung zu noch größerer Gier, die dann mit Überrennung des Verstandes, die Verteidigungspläne zu ihren Zwecken willkürlich ändert. (B 586) 
Es ist die Gier, die zur Änderung der Pläne und folglich zur Panik führt. Sie ändert die „Verteidigungspläne zu ihren Zwecken“. In einer eigentümlichen Logik wird mit dieser Formulierung der Gier Handlungsmacht und die Fähigkeit zum planvollen Handeln zugesprochen. Die Gier bekommt subjektähnlichen Status, wird ein Feind des Protagonisten, obwohl sie Teil desselben ist. Die Frage stellt sich, ob der Bau nicht auch zum Schutz des Erzählers vor sich selbst erbaut wurde. ${ }^{505}$ Die Ambivalenz erfährt im Verlauf der Erzählung weder eine Auflösung noch eine Präzisierung. Stattdessen scheint eine $\mathrm{Zu}-$ spitzung am Werk zu sein, die sich in den andauernden Variationen der paranoiden Erzählstimme äußert und schließlich in die Performanz der Erzählung selbst mündet. 506

Das Verhältnis zwischen Planung und Ordnung ist, wie oben gezeigt wurde, wechselseitig: Einerseits ist Planung Ausdruck von Ordnung, andererseits stellt sie Ordnung her. In Der Bau lässt Planung in erster Linie Kontingenz entstehen. Sie schafft nicht Ordnung im Sinn einer Komplexitätsreduktion der Zukunft, sondern ist Ausdruck einer Ordnung der Unsicherheit und Spontaneität, die fortwährend erzeugt wird. In diesem Vorwärtstreiben der Ordnungsbemühungen ist nicht mehr die Ordnung als Produkt wichtig, sondern der sich in der Ablösung vom Subjekt verselbstständigende Prozess des Ordnens selbst.

\section{Geplante Panik}

Nicht immer ist im Text das Planen als panisches Handeln gefasst. Es gibt Szenen, in denen Planen und Handeln als Gegensätze etabliert werden. Die Planung muss abgebrochen werden, damit der Protagonist handlungsfähig wird. Dies zeigt sich eindrücklich beim Wiedereintritt des Protagonisten in seinen Bau, der nur durch Unterbrechen der Reflexion über die richtige Methode gelingen kann: Der Erzähler zögert die Rückkehr in den Bau hinaus, aus Sorge, auf sein Versteck aufmerksam zu machen, es so in Gefahr zu bringen. Auf der Suche nach dem sicheren Weg zurück scheint er zunächst streng methodisch vorzugehen:

\footnotetext{
505 Vgl. dazu Hiebel, der darauf besteht, dass der Gegner nicht der Protagonist selbst ist: „Dennoch bleibt der Gegner ein ,Anderer" - sei's im Innern, sei’s im Äußeren!" Hiebel, Franz Kafka, 28. Siehe Kap. 4.1.2 Ich und das Andere, S. 211f. oben.

5 o6 Vgl. Hans Hiebels Konzept der "gleitenden Metapher“, das den Prozess der Semiose im Sinn von Derridas différance aufgreift. Hiebel, 13-50, 129-163. Der Bau sei dabei ein "gutes Beispiel für das Prozeßhafte der Sinngebung Kafkas, d. h. für die changierende, gleitende, prozessierende Metapher“. Hiebel, 26. Vgl. auch das "gleitende Paradox“ bei Gerhard Neumann, „Umkehrung und Ablenkung. Franz Kafkas ,Gleitendes Paradox‘ [1968]“, in Kafka-Lektüren (Berlin, Boston: De Gruyter, 2012), 355-401.
} 
Ich grabe, natürlich in genügender Entfernung vom wirklichen Eingang, einen Versuchsgraben, er ist nicht länger als ich selbst bin und auch von einer Moosdecke abgeschlossen. Ich krieche in den Graben, decke ihn hinter mir zu, warte sorgfältig berechnete kürzere und längere Zeiten zu verschiedenen Tagesstunden, werfe dann das Moos ab, komme hervor und registriere meine Beobachtungen. Ich mache die verschiedensten Erfahrungen, guter und schlimmer Art, ein allgemeines Gesetz oder eine unfehlbare Methode des Hinabsteigens finde ich aber nicht. (B 594)

Aus der Erkenntnis, dass die Möglichkeit des Beobachtetwerdens immer besteht, verfällt das Erzähler-Ich jedoch nicht auf die pragmatische Haltung, das Unausweichliche hinzunehmen und trotz der aporetischen Situation in den Bau einzutreten. Der Protagonist muss sich und seine leerlaufende Methodik sozusagen überlisten. Erst wenn er von der panischen Planung völlig erschöpft ist, „denkunfähig von Müdigkeit“ (B 6o2), kann er sich mit letzter Kraft in den Bau werfen. Denkunfähigkeit meint das Ausschalten der Planungsmaschinerie, das Einstellen der Proliferation von Befürchtungen auf der Suche nach der optimalen Lösung. Die paranoide Planung verhindert die Handlung, die Methodik macht den Entscheid unmöglich, weil der Protagonist sich in einer Aporie befindet, in der er nicht gleichzeitig beobachten und handeln kann.

Durch die iterative Erzählweise, das einmalige Erzählen eines sich wiederholenden Ereignisses, ${ }^{507}$ wird gleichwohl immer wieder der Eindruck erzeugt, es handle sich um ein planvolles Vorgehen des Erzählers, weil diese Handlungssequenz immer gleich abläuft und er entsprechend wissen müsste, wie er zu handeln hat und welche Wirkung diese Handlung bzw. Planung haben wird. Die Lösung besteht in einem zwangsläufig geplanten Planausfall, im Einberechnen der Unberechenbarkeit. Dieser prekäre Status der Planung wirft auch ein neues Licht auf den Bau selbst, dessen Bauweise und Eigenschaften auf genauen Plänen und Berechnungen beruhen sollen.

\subsubsection{Der „Gesamtplan“. Aporetische Genese des Baus}

Fragwürdig sind nicht nur die Behauptungen des Erzählers über seine planerischen Fähigkeiten, sondern auch der konkrete Bauplan des Baus, dessen Topografie uneindeutig ist. Im Zusammenhang mit seinem Wunsch nach einem zweiten Hauptplatz, der eine weitere Absicherung der Vorräte mit sich bringen soll, erwähnt der Erzähler einen „Gesamtplan“, den er als Grund

507 Das iterative Erzählen steht im Gegensatz zum singulativen Erzählen, in welchem ein jeweils einmaliges Ereignis einmal erzählt wird sowie dem repetitiven Erzählen, welches ein einmaliges Ereignis mehrfach erzählt. Vgl. Genette, Die Erzählung, 73-81. Siehe Kap. 4.2 Iteration, Singulation und die prekäre Ordnung der Zeit, S. 224ff. unten. 
dafür nennt, dass ebendieser zweite Hauptplatz nicht gebaut werden kann. Es bleibt unklar, ob dies nur deshalb nicht möglich ist, weil der Plan es nicht vorsieht oder weil es keinen Raum für weitere Plätze in der Art des Burgplatzes gibt: „Auch sind sie [die Plätze] im Gesamtplan meines Baues jetzt nachträglich nicht mehr unterzubringen.“ (B 584) Ähnlich heißt es wenig später: „[S]o sorgfältig ich den Eingang abseitsliegend gewählt habe - der Gesamtplan legte mir allerdings darin gewisse Einschränkungen auf" (B 591). Deutlich ist, dass der Bau nach und nach entstanden ist. Bereits im zweiten Satz werden Forschungsgänge und aufgegebene Versuche beschrieben:

Von außen ist eigentlich nur ein großes Loch sichtbar, dieses führt aber in Wirklichkeit nirgends hin, schon nach ein paar Schritten stößt man auf natürliches festes Gestein, ich will mich nicht dessen rühmen diese List mit Absicht ausgeführt zu haben, es war vielmehr der Rest eines der vielen vergeblichen Bauversuche, aber schließlich schien es mir vorteilhaft, dieses eine Loch unverschüttet zu lassen. (B 576)

Mit diesem zweiten Satz wird der eigentliche Anfang der Erzählung gleichsam aufgeschoben. Anstatt mit dem richtigen Eingang zu beginnen, führt der Text zunächst zur Attrappe. Dabei ist auch der Leser immer schon miteinbezogen: Sowohl ist es eine Attrappe für mögliche Feinde des Erzählers als auch eine Verwirrung des Lesers des Baus. ${ }^{508}$ Am Eingangsbereich ist die Genese des Baus besonders deutlich zu erkennen:

[D]ort [beim Eingang] fing mein Bau an, ich durfte damals noch nicht hoffen ihn je so beenden zu können, wie er in meinem Plane dastand, ich begann halb spielerisch an diesem Eckchen und so tobte sich dort die erste Arbeitsfreude in einem Labyrintbau aus, der mir damals die Krone aller Bauten schien, den ich aber heute wahrscheinlich richtiger als allzu kleinliche, des Gesamtbaues nicht recht würdige Bastelei beurteile [...]. (B 586f.)

Die anfängliche Hoffnung, den Bau so „beenden zu können, wie er in meinem Plane dastand“, steht in bemerkenswerter Spannung zum Umstand, dass sich die Bewertung des Labyrinths radikal geändert hat:Von der „Krone aller Bauten“ verkommt es zu einer „Bastelei“. Da der Plan schon von Beginn an aufgestellt zu sein scheint, muss das Labyrinth Teil davon sein und doch auch wieder

508 Dieser Aufschub des Beginns ist bei Kafka auf ganz andere Weise gestaltet als bei Robert Walser. Walser macht den Erzählprozess jeweils explizit, wie besonders anschaulich an der Eingangssequenz des Spaziergangs zu sehen ist. Bei Kafka wird mehrheitlich auf metanarrative Einschübe verzichtet, bzw. sind diese implizit in der Bildlichkeit zu decodieren. Siehe Kap. 3.2 Digression als prekäres Ordnungsverfahren, S. 116ff.; Kap. 3.4.3 Sättigender Hunger. Auflauf S. 125ff., oben. 
nicht; er ist also widersprüchlich codiert. ${ }^{509}$ Daraus erwächst eine eigentliche Aporie zwischen der Genese und dem Werk - erstere führt zum Werk, letzteres stellt erstere als widersprüchlich dar, wodurch diese wiederum ihre Wirkungskraft zur Genese des Werks verliert. ${ }^{510}$ Es finden inhaltliche Verschiebungen in der Planung und im Plan statt, Bewertungen und Einschätzungen ändern sich, ohne dass diese angezeigt würden. Das ist eine denkbar schlechte Voraussetzung, verlässliche Pläne zu konstruieren. Die Genese des Werks, ihre Verfahren und ihre Planbarkeit werden so widersprüchlich. In dieser figurativen Unmöglichkeit des Erzählens zeigt sich das Prekäre desselben, ist diese Unmöglichkeit doch konstitutiv für den Text.

Auch zeigt sich, wie schon in der Diskussion um die Subjektivierung der Gier erwähnt, wie sich eine Regung des Protagonisten in den Vordergrund drängt, sich geradezu vom Ich abspaltet und Subjektcharakter gewinnt. Es ist die „Arbeitsfreude“, die sich "in einem Labyrintbau“ austobt (B 586) und nicht der Protagonist. Im Nachhinein kritisiert das Erzähler-Ich das „kleine[] tolle[] Zickzackwerk" (B 586) im Eingangsbereich des Baus, weil es überhaupt erst darauf hinweist, dass es etwas zu verstecken gibt.

Tatsächlich scheint das Labyrinth keine gute Idee gewesen zu sein. Für Jagdtiere und insbesondere Grabtiere, die auf den Geruchssinn und andere Wahrnehmungen setzen, dürfte ein solches Labyrinth, das vor allem die visuelle Wahrnehmung herausfordert, kein großes Hindernis darstellen. ${ }^{511}$ Wie sinnlos und unpraktisch es jedoch in anderer Hinsicht ist, wird nicht ausgesprochen. So bleibt außer acht, wie mühsam es für den Protagonisten ist, die Beute, die er draußen in nicht geringem Masse jagt, einzubringen. Diese muss er nämlich durch die „engen und schwachwandigen Gänge des Labyrinthes“ (B 6о3) vor sich herschieben.

509 Vgl. die Schreibweise mit doppeltem "m“ etwas später: „Gesammtbaues“ (B 587, Zeile 25). Es ist auffällig, dass Kafka dies nicht korrigierte, hat er doch in derselben Zeile eine Korrektur eingefügt, vgl. Kafka, Nachgelassene Schriften und Fragmente II. Appartband, 433. Eine spekulative Lektüre könnte dies als Hinweis auf die Existenz von mehreren Gesamtplänen nehmen.

510 In diesem Doublebind sehen viele Arbeiten zum Bau eine Metapher für Kafkas gesamtes Werk. So Kurz: „Das Verhältnis zwischen dem Ich und seinem Bau läßt sich unschwer auf das Verhältnis des Autors Franz Kafka zu seinem Werk beziehen.“ Gerhard Kurz, „Das Rauschen der Stille. Annäherungen an Kafkas ,Der Bau“', in Franz Kafka. Zur ethischen und ästhetischen Rechtfertigung, hg. von Beatrice Sandberg und Jakob Lothe (Freiburg im Breisgau: Rombach, 2002), 16o. Vgl. grundlegend für die These der Metapher des gesamten Werks: Corngold, Franz Kafka. The Necessity of Form.

511 Auch dies kann als Hinweis darauf gelesen werden, dass es sich beim Graben des Tiers nicht um ein arttypisches Verhalten handelt, würde es andernfalls doch Schutzmethoden verwenden, die wirksam wären gegen feindliche Grabtiere. 
Ich drücke vorwärts mit allen Kräften und es geht auch, aber mir viel zu langsam; um es zu beschleunigen reiße ich einen Teil der Fleischmassen zurück und dränge mich über sie hinweg, durch sie hindurch, nun habe ich bloß einen Teil vor mir, nun ist es leichter ihn vorwärtszubringen, aber ich bin derart mitten darin in der Fülle des Fleisches hier in den engen Gängen [...], daß ich recht gut in meinen eigenen Vorräten ersticken könnte, manchmal kann ich mich schon nur durch Fressen und Trinken vor ihrem Andrang bewahren. (B 6o3f.)

Es ist eine deutliche Fehlplanung, keinen Versorgungszugang zu berücksichtigen, der ein reibungsloses Einbringen der Beute ermöglicht. Dass das Erzähler-Ich gerade dieses Problem nicht zum Anlass nimmt, sich zu sorgen, irritiert.

Dieser Umstand hängt mit der Art und Weise des Erzählens zusammen. Das Einbringen der Beute wird in einer Sequenz berichtet, in der die den Bau prägende Spannung zwischen iterativer und singulativer Erzählweise besonders prägnant ist. Auch auffällig ist, dass das eigentliche Einbringen der Beute im Übergang von außen nach innen nur an einer Stelle geschildert wird: „Ich versuche es zunächst in stürmischen Nächten mit dem schnellen Hineinwerfen der Beute" (B 594). Ansonsten ist die Beute immer schon im Gang und wird beim Wiedereinstieg des Protagonisten nur noch zum Burgplatz gebracht. Es ist dies die inhaltliche Folge einer formalen Eigenheit der Erzählweise des Baus, dass nur das zu existieren scheint, was ausgesprochen wird: Die stillschweigend vorausgesetzten Bedingungen von Raum und Zeit, von Kausalität und Logik sind im Bau in dieser radikalen Form solipsistischen Erzählens aufgehoben. Die hochselektive Wahrnehmung des Erzählers ist konstitutiv für die erzählte Welt. Es gibt kein übergeordnetes Gedächtnis, keine gültige Ordnung, keine objektive Übersicht. Außerhalb des Baus - als Erzählung wie als Erzähltes - existiert nichts. ${ }^{512}$

\subsubsection{Der Bau als prekäre Ordnung}

Der Text lässt offen, von welcher Art die Planung des Baus war und inwiefern tatsächlich von einer durchgehenden Planung gesprochen werden kann. Die Beschreibung des Baus weist eher auf eine diskontinuierliche, spontane Neubildung und Fortführung desselben hin, als auf die Ausführung eines feststehenden Plans, trotz anderweitiger Aussage des Erzähler-Ich. Es wird immer auch deutlich, dass der Erzähler viel Wert auf die Planbarkeit seines Verhaltens

512 Aus dieser Einsicht ließen sich auch Argumente für eine Lektüre des Textes als selffulfilling prophecy gewinnen, die den Schluss des Textes als Kampf zwischen "Zischer“ und Erzähler modelliert. Denn wenn alles, was der Erzähler erzählt, in der Erzählung wahr ist, dann wäre es auch die feindliche Existenz des "Zischers“. 
wie jenes der Umwelt legt. Auch dem „Zischer“ schreibt der Erzähler ein planvolles Vorgehen zu: „Dabei wirkt mit, daß das Tier nicht auf mich zugeht, darum ändert sich das Geräusch nicht, es liegt vielmehr ein Plan vor, dessen Sinn ich nicht durchschaue" (B 623).

Auf offensichtliche Art und Weise fungiert der Bau als Metapher für Ordnung. Diese Ordnung ist prekär, da sie auf der solipsistischen Perspektive des Urhebers, des Erzählers beruht. Die Vision des Erzählers für eine Lösung des Konflikts der Sicherheit des Baus und seinem Teilhaben an dieser Sicherheit besteht im Paradox einer Aufhebung von Innen und Außen. Er imaginiert sich zum einen zwei Eingänge, womit er sich selbst beim Eintritt beobachten könnte. Zum anderen erträumt er sich eine Art Vorhöhle um den Burgplatz. Diese Aporie zwischen Innen und Außen, der Unmöglichkeit gleichzeitig innen und außen zu sein, besteht jedoch im Raum selbst und ist mit Architektur nicht aufzulösen. Wie das Ich in seiner Funktion als Figur und Protagonist den Bau gräbt, so erzeugt es in seiner Funktion als Erzähler die prekäre Ordnung der Erzählung. In den paradoxen Verfahren entsteht ein prozessualer Bau, eine fluktuierende Ordnung. Der Text selbst wird in seiner Unbestimmtheit zu jener utopischen Vorhöhle, zum zweiten Eingang, von dem aus sich der Erzähler beim Einstieg beobachtet.

\subsection{Iteration, Singulation und die prekäre Ordnung der Zeit}

Bei Fontanes Der Stechlin hat sich herausgestellt, dass eine Spannung zwischen den Figuren und ihrer Darstellung, der story und dem discourse besteht. Der discourse versucht, die Ambivalenz auf der story-Ebene zu kontrollieren und erzeugt zugleich neue Ambivalenz. Kafkas Bau dagegen lebt geradezu von den oben herausgearbeiteten Ambivalenzen auf der story-Ebene und in der Semantik der Zuschreibungen. Dies gilt nicht nur für den Raum im Bau sondern auch für die Zeitdarstellung.

Die story des Baus ist simpel und handlungsarm: Der Protagonist verbringt die erzählte Zeit, von einem Ausflug abgesehen, in seinem Bau, nimmt einige Ausbesserungen vor und gibt sich seinen hypersensiblen, auf paranoiden Denkmustern beruhenden Gedanken und Beobachtungen hin. Mittels eines discourse, der die paradoxe Erzählsituation erzeugt, in der durch gleichzeitig iterativ und singulativ markierte Erzählweise nicht mehr unterschieden werden kann, ob ein Ereignis gerade geschieht oder schon geschehen ist, wird die Prekarität der Geschichte gesteigert. Im Versuch, die erzählte Welt in ständig variierten Plänen zu ordnen, radikalisiert der Erzähler deren Unbestimmtheit. 
Es ist unklar, was Wahnvorstellung und was Wirklichkeit, was Gegenwart und was Vergangenheit ist. Letztlich wird die Kontingenz der Welt des Baus als Konstruktion der Erzählung herausgestellt.

\subsubsection{Zur „Trunkenheit der Iteration“. Paradoxie der Zeitordnung}

Gérard Genette handelt iteratives und singulatives Erzählen in der Kategorie der Frequenz ab. Er unterscheidet zwischen repetitiver (ein Ereignis mehrfach erzählen), singulativer (ein Ereignis einmal erzählen) und iterativer (mehrere sich wiederholende Ereignisse einmal erzählen) Erzählweise. ${ }^{513}$ In seinem Referenzwerk, Marcel Prousts ̀̀ la recherche du temps perdu, hat Genette eigenartige Überblendungen von Iteration und Singulation vorgefunden. $\mathrm{Er}$ analysiert die Sequenzen, in denen Proust "inmitten einer iterativ gestalteten Szene ein Passé simple unter die Feder kommt, das notwendigerweise singulativ ist". ${ }^{\prime \prime} 14$

Man kann diese scheinbaren Nachlässigkeiten natürlich als Spuren einer ersten singulativen Redaktion auffassen, so dass Proust also nur vergessen hätte, einigen Verben die richtige Zeitform zu geben, aber angemessener scheint es mir zu sein, diese Schnitzer als ebenso viele Zeichen dafür anzusehen, dass der Schriftsteller mitunter solche Szenen am Ende mit einer Intensität ,erlebt', die ihn die Unterscheidung der Aspekte vergessen lässt [...]. Diese Vermengungen deuten bei Proust, wie mir scheint, eher auf eine Art Trunkenheit der Iteration hin. ${ }^{15}$

Was Genette „Schnitzer“ nennt, hat bei Kafka System; Überblendungen von Iteration und Singulation tauchen regelmäßig auf. Kommt hinzu, dass sowohl bei Proust als auch bei Kafka die Zeit inhaltlich wie formal ein zentrales Thema ist. Kann man beim Bau auch von einer „Trunkenheit der Iteration“ sprechen? Davon, dass Kafka - bei Genette heißt es explizit "der Schriftsteller" - aufgrund der Identifikation mit dem Erzählten den grammatischen Aspekt vernachlässigt? Angesichts der emotionalen Involviertheit des Erzählers in einigen Sequenzen, die sich in der metanarrativen Sprachverwendung äußert, ist dies nicht ausgeschlossen. Jedoch gibt es bei Kafka auch den umgekehrten Fall: das Einschleichen der Iteration in den Singulativ. Diese Form lässt sich kaum mit Genettes Rückgriff auf den Autor erklären. Zudem ist die Durchdringung der Erzählung von solchen Überblendungen weit mehr fortgeschritten und für den Bau selbst konstitutiv. Dennoch können diese Überblendungen als Spuren

\footnotetext{
513 Genette, Die Erzählung, 73-102.

514 Genette, 79 .

515 Genette, 79. Hervorhebung i. O.
} 
der Herstellung, also als impliziter metafiktionaler Kommentar des Erzählers gelesen werden, der den Bau als paradoxes Unternehmen erscheinen lässt.

In Der Bau sind weite Teile, insbesondere der Anfang, im Iterativ erzählt. Der Erzähler schildert sein gewohnheitsmäßiges Leben, erzählt von der Herstellung des Baus, den Gefahren im Bau und gibt Hinweise auf deren Ursachen. Entsprechend seiner zeitlichen Gestaltung wurde Der Bau immer wieder als zweiteilige Erzählung gelesen: Im ersten Teil wird im Iterativ von den Gewohnheiten des Erzählers und dem Entstehen des Baus berichtet. Nach dem Schlaf, dessen Ende durch das Aufkommen des Zischens herbeigeführt wird, wechselt die Erzählung sodann in den Singulativ. ${ }^{516}$ Belege für das iterative Erzählen finden sich viele; Marker sind Adverbien, die den Wiederholungscharakter betonen und Verben, die Gewohnheit anzeigen.

Das schönste an meinem Bau ist aber seine Stille, freilich sie ist trügerisch, plötzlich einmal kann sie unterbrochen werden und alles ist zu ende, vorläufig aber ist sie noch da, stundenlang kann ich durch meine Gänge schleichen und höre nichts als manchmal das Rascheln irgendeines Kleintiers, das ich dann gleich zwischen meinen Zähnen auch zur Ruhe bringe, oder das Rieseln der Erde, das mir die Notwendigkeit irgendeiner Ausbesserung anzeigt, sonst ist es still. Die Waldluft weht herein, es ist gleichzeitig warm und kühl, manchmal strecke ich mich aus und drehe mich in dem Gang rundum vor Behagen. Schön ist es für das nahende Alter einen solchen Bau zu haben, sich unter Dach gebracht zu haben, wenn der Herbst beginnt. (B 579)

Ein lang andauernder Zustand wird beschrieben, der jedoch von einem einzelnen Ereignis zerstört werden kann. Die Stille ist immer nur „vorläufig“ intakt. Die Worte „plötzlich“ und „einmal“ betonen den singulativen Charakter des möglichen Ereignisses, der Katastrophe als Zerstörung der Stille. Der Zustand als Iteration ist positiv konnotiert, während das singulative Ereignis als Aufhebung des Zustandes eingeführt wird. Regelmäßig „schleicht“ der Erzähler durch die Gänge, frisst störendes „Kleintier“ und bessert den Bau aus. Das sind Zustandsbeschreibungen, die ambivalent sind: Schleichen weist auf eine Bedrohung oder eine Kampfsituation hin, das „Kleintier“ beweist die Porosität des Baus und die Notwendigkeit ständiger Ausbesserungen dessen Fragilität.

516 Vgl. etwa Dorrit Cohn, Transparent Minds. Narrative Modes for Presenting Consciousness in Fiction (Princeton: Princeton University Press, 1978); Dennerlein, „Die Zerstörung des idealen Habitats als unerhörte Begebenheit“; Liska, „,Der Bau““. Nicht dieser Ansicht sind: John M. Coetzee: „Time, Tense and Aspect in Kafka's ,The Burrow“'. In: MLN (1981), S. 556579; wiederabgedruckt auf Deutsch in: John M. Coetzee: „Zeit, Tempus und Aktionsart in Kafkas ,Der Bau'،, in Der Präsensroman, herausgegeben von Armen Avanessian und Anke Hennig (Berlin, Boston: De Gruyter, 2013), 79-100; Henel: „Das Ende von Kafkas ,Der Bau““. 
Die Zweiteilung des Textes in einen iterativen Teil vor und einen singulativen Teil nach dem Schlaf ist jedoch nicht so deutlich, wie gemeinhin formuliert wird. ${ }^{517}$ Das Singulative ist zum einen hauptsächlich im Erzählvorgang, in der punktuell akzentuierten Erzählgeschichte, dominant. ${ }^{518}$ Der Erzähler nimmt, wie im obigen Zitat deutlich, durchaus eine Position in der erzählten Zeit ein, wenn auch eine zwischen „Höhepunkt" (B 577) und "Herbst“ (B 579) seines Lebens schwankende. Mit Gérard Genettes weiteren Differenzierungen der Frequenz lässt sich zum anderen sagen, dass die Iteration im zweiten Teil des Baus nicht suspendiert ist, sondern hinsichtlich der Determination, der "diachronischen Grenzen“, der Spezifikation, der "rhythmische[n] Wiederkehr ihrer konstitutiven Einheiten" unbestimmter wird. 519

Bemerkenswert an der Zeitstruktur des Baus sind gerade die Überblendungen von iterativer und singulativer Erzählweise, die die Ordnung der Erzählung fundamental erschüttern. Ein eindrückliches Beispiel einer solchen Überblendung lässt sich in der Szene finden, in der der Erzähler den Bau verlässt. Der Erzähler berichtet, durch die Wendung ,ich pflege zu tun` und den Partikel ,öfters' deutlich den Iterativ markierend, wie er nach den zyklischen Umverteilungen der Vorräte und den jeweiligen Fressattacken den Bau verlässt: „Nach solchen Zeiten pflege ich um mich zu sammeln den Bau zu revidieren und nachdem die nötigen Ausbesserungen vorgenommen sind, ihn öfters wenn auch immer nur für kürzere Zeit zu verlassen." (B 586 ${ }^{520}$

Es folgt eine längere Reflexion des Erzählers über das Labyrinth im Eingangsbereich, über die Qualen, die er jeweils in dessen Nähe erleidet, die

517 So etwa bei Dorrit Cohn: „The static time of the first part of the story now becomes an evolving time, its durative tense a punctual tense“. Cohn, Transparent Minds. Narrative Modes for Presenting Consciousness in Fiction, 197. Oder explizit mit Genettes Nomenklatur bei Manfred Engel: „Im zweiten Teil des Textes (der vom Iterativ in den Singulativ, also die Erzählung einmaliger Ereignisse, wechselt)“. Manfred Engel, „Kafka und die moderne Welt", in Kafka-Handbuch. Leben - Werk - Wirkung, hg. von Manfred Engel und Bernd Auerochs (Stuttgart: Metzler, 2010), 510. Dagegen weist John Coetzee darauf hin, dass auch nach dem Schlaf noch iterative Sequenzen vorkommen: „Es finden zu häufig Verlagerungen statt, als dass Cohns Verallgemeinerung zutreffen könnte.“ Coetzee, „Zeit, Tempus und Aktionsart in Kafkas ,Der Bau““, 87. Vgl. zu Kafkas Verwendung des Präsens auch Dorrit Cohn, „Kafka's Eternal Present: Narrative Tense in ,Ein Landarzt' and Other First-Person Stories", PMLA 83, Nr. 1 (März 1968): 144, https://doi.org/10.2307/1261242.

518 Für den Aspekt der Erzählgeschichte siehe Kap. 3.3.1 Zum Begriff der Performanz in der Narratologie, S. 168ff. oben.

519 Genette, Die Erzählung, 82.

520 Die oben diskutierte Spannung in Bezug auf die Jagd ist auch hier greifbar. An anderer Stelle heißt es, dass der Erzähler regelmäßig zur Jagd nach draußen gehe; hier dagegen scheint das Verlassen des Baus eine Art Selbstgeißelung oder eine Form von Selbstbesinnung zu sein. 
Möglichkeiten eines Umbaus, die Gefahren, die sich daraus ergeben würden, und schließlich wird von einem wiederkehrenden Traum berichtet, in dem der Erzähler alles „mit Riesenkräften, in einer Nacht“ (B 588) umbaut. Es folgt der Aufbruch, in dem sich singulative und iterative Erzählelemente überschneiden.

Die Pein dieses Labyrinthes muß ich also auch körperlich überwinden, wenn ich ausgehe [...]. Dann aber bin ich unter der Moosdecke, der ich manchmal Zeit lasse - solange rühre ich mich nicht aus dem Hause -, mit dem übrigen Waldboden zusammenzuwachsen und nun ist nur noch ein Ruck des Kopfes nötig und ich bin in der Fremde. Diese kleine Bewegung wage ich lange nicht auszuführen, hätte ich nicht wieder das Eingangslabyrinth zu überwinden, gewiß würde ich heute davon ablassen und wieder zurückwandern. Wie? Dein Haus ist geschützt, in sich abgeschlossen, Du lebst in Frieden, warm, gut genährt, Herr, alleiniger Herr über eine Vielzahl von Gängen und Plätzen, und alles dieses willst $\mathrm{Du}$, hoffentlich nicht opfern, aber doch gewissermaßen preisgeben, hast zwar die Zuversicht es zurückzugewinnen, aber läßt Dich doch darauf ein, ein hohes, ein allzuhohes Spiel zu spielen. Es gäbe vernünftige Gründe dafür? Nein, für derartiges kann es keine vernünftigen Gründe geben. Aber dann hebe ich doch vorsichtig die Falltüre und bin draußen; lasse sie vorsichtig sinken und jage, so schnell ich kann, weg von dem verräterischen Ort. (B 58gf.)

Mit dem Bedingungssatz "wenn ich ausgehe“, dem anschließenden „dann“ sowie dem "manchmal“ ist deutlich der Iterativ markiert. Ebenfalls deutlich ist die Singulation beim Herausstreichen der Einzigartigkeit der jetzigen Situation: Nur heute würde der Erzähler zurückkehren. Auch die metanarrative Selbstansprache weist als innerer Monolog auf Singulation. ${ }^{521}$ Vermischt werden die Erzählfrequenzen im Teilsatz „nun ist nur noch ein Ruck des Kopfes nötig“. Hier kennzeichnet das "nun“ die Umstellung auf die einmalige Situation, gleichzeitig kann es als Vergegenwärtigung der wiederkehrenden Handlung verstanden werden. Ähnliches gilt für die Sequenz des Hebens der Falltür, in der die Wendung „aber dann“ sowohl iterativ als auch singulativ gelesen werden kann.

Es ist auffällig, dass die Unentscheidbarkeit zwischen Iteration und Singulation außerhalb des Baus deutlicher ist als innerhalb. Zahlreiche deiktische Ausdrücke, relationale, auf einen Betrachter hinweisende Adverbien - hier, dort -, stehen in Konflikt mit deutlich iterativen Sätzen wie folgendem: „Mir ist dann, als stehe ich nicht vor meinem Haus, sondern vor mir selbst, während ich schlafe, und hätte das Glück gleichzeitig tief zu

521 Diese Selbstansprachen kommen auch bei Robert Walser vor. Bei Walser stellt sich das Befremden als Normverletzung auf der Ebene der Ontologie ein, indem etwa der Erzähler den Verfasser anspricht. Bei Kafka handelt es sich nicht um eine Metalepse. Das Befremden resultiert aus einer paradoxen Zeitlichkeit. 
schlafen und dabei mich scharf bewachen zu können." (B 591) Nachträglich wird dieser ,Iterativ des Schlafs' vor dem Höhleneingang in einen Singulativ verwandelt: „Nein, ich beobachte doch nicht wie ich glaubte meinen Schlaf, vielmehr bin ich es der schläft, während der Verderber wacht." (B 593) Das vorhergehende Beobachten des Schlafes wird durch das Präteritum („wie ich glaubte") als Singulativ markiert. Eine Erkenntnis kann, da sie den Übergang vom Nichtwissen zum Wissen darstellt, nur singulär sein. Iterative Erkenntnis ist nicht möglich, weil die Iteration das Wissen um die Wiederholung voraussetzt. Mittels solcher Ambivalenzen, die in der paradoxen Vorstellung des Beobachtens des eigenen Schlafes ihre inhaltliche Entsprechung finden, wird die Frage nach dem Ereignis virulent: Kommt es nun in dieser paradoxen Situation zwischen Iterativ und Singulativ, die unter den herkömmlichen lebensweltlichen Prämissen unmöglich ist, zu einer Handlung oder nicht?522 Beim Wiedereinstieg in den Bau findet sich der deutlichste Widerspruch bezüglich der Frequenz.

Und nun, schon denkunfähig von Müdigkeit, mit hängendem Kopf, unsicheren Beinen, halb schlafend, mehr tastend als gehend nähere ich mich dem Eingang, hebe langsam das Moos, steige langsam hinab, lasse aus Zerstreutheit den Eingang überflüssig lange unbedeckt, erinnere mich dann an das Versäumte, steige wieder hinauf um es nachzuholen, aber warum denn hinaufsteigen? nur die Moosdecke soll ich zuziehn, gut, so steige ich wieder hinunter und nun endlich ziehe ich die Moosdecke zu. Nur in diesem Zustand, ausschließlich in diesem Zustand kann ich diese Sache ausführen. [...] Nichts stört mich, niemand ist mir gefolgt, über dem Moos scheint es wenigstens bis jetzt ruhig zu sein und selbst wenn es nicht ruhig wäre, ich glaube, ich könnte mich jetzt nicht mit Beobachtungen aufhalten, ich habe den Ort gewechselt, aus der Oberwelt bin ich in meinen Bau gekommen und ich fühle die Wirkung dessen sofort. Es ist eine neue Welt, die neue Kräfte gibt und was oben Müdigkeit ist, gilt hier nicht als solche. (B 6ozf.)

Auffallend ist, mit welcher Detailtreue der Einstieg beschrieben wird, auch das nochmalige Hinaufsteigen wird geschildert. Mehr noch als dies ist es die Selbstkorrektur in diesen Zeilen, die wirken, als würde der Erzähler zeitgleich erzählen und handeln, dass sich also Erzählzeit und erzählte Zeit decken. Auch die Marker "bis jetzt" sowie die unmittelbare Wirkung des Baus auf das Erzähler-Ich deuten auf ein singulatives Erzählen. Dennoch gibt es auch

522 Vgl. zu einer strengen Definition des Ereignisses, die die Singularität hervorhebt: Hühn, „Event and Eventfulness“. Wolf Schmid betont die Bedeutung der „Non-Iterativität" explizit: „Veränderungen, die sich wiederholen, konstituieren, selbst wenn sie relevant und imprädiktabel sind, bestenfalls nur geringe Ereignishaftigkeit." Schmid, Elemente der Narratologie, 19 . 
Hinweise auf Iteration, etwa das einführende „und nun, schon“ sowie der Umstand, dass der Erzähler weiß, dass er „aus Zerstreutheit“ den Eingang offen lässt: Dass man zerstreut war, lässt sich ausschließlich retrospektiv beurteilen. Sobald man sich seiner Zerstreutheit bewusst wird, löst sie sich auf. Ins Auge sticht jedoch der Satz „Nur in diesem Zustand, ausschließlich in diesem Zustand kann ich diese Sache ausführen“, der die Szene eindeutig in die Iteration kippen lässt: Dass der Protagonist weiß, dass es diesen bestimmten Zustand braucht, um eintreten zu können, impliziert, dass er die Handlung regelmäßig ausführt. Er spricht aus Erfahrung. Der Fortgang der Szene stellt sich dann deutlich wieder als singulative Handlung dar.

Auffällig an dieser Sequenz ist auch die hohe emotionale Involviertheit des Erzählers. Dies deutet ebenfalls darauf hin, dass es sich um ein einmaliges Erlebnis handelt. Dasselbe Muster ist aktiv, als der Erzähler versucht, seine Beute einzubringen und sich mühsam durch den Gang hinab durch das eingelagerte Fleisch kämpfen muss.

Die erste Arbeit ist sehr mühselig und nimmt mich ganz in Anspruch: die Beute nämlich durch die engen und schwachwandigen Gänge des Labyrinthes zu bringen. Ich drücke vorwärts mit allen Kräften und es geht auch, aber mir viel zu langsam; [...] aber ich bin derart mitten darin in der Fülle des Fleisches hier in den engen Gängen, [...] daß ich recht gut in meinen eigenen Vorräten ersticken könnte, manchmal kann ich mich schon nur durch Fressen und Trinken vor ihrem Andrang bewahren. [...] Aber der Transport gelingt [...]. Nun ist es keine Arbeit mehr, nun rollt und fließt das Ganze fast von selbst hinab. Endlich auf meinem Burgplatz! Endlich werde ich ruhen dürfen. Alles ist unverändert, kein größeres Unglück scheint geschehen zu sein, die kleinen Schäden, die ich auf den ersten Blick bemerke, werden bald verbessert sein. (6o3f.) $)^{523}$

Die Spannung zwischen dem Iterativ („[d]ie erste Arbeit ist mühselig“) und den folgenden Sätzen, die singulativ formuliert sind, ist deutlich. Im Verlauf dieser Schilderung nähern sich die Sätze immer mehr dem Erzählzeitpunkt an und enden schließlich mit dem Ausruf „Endlich auf meinem Burgplatz!“ in einem simultanen Erzählen als dramatische Rede. ${ }^{524}$

Anzunehmen, bei jedem Verlassen des Baus und jeder Rückkehr in ihn liefe der gleiche Prozess ab, ist - im Widerspruch zu der durch den Iterativ suggerierten Regelmäßigkeit - absurd. Der Iterativ garantiert in seiner

523 Im Sinn Hiebels „gleitender Metapher“ lassen sich eine Vielzahl Metaphorisierungen für diese Szene ausdenken. Hiebel erwägt hier eine Lesart der „umgekehrten Geburt“. Vgl. Hiebel, Franz Kafka.

524 Gérard Genette unterscheidet in der Distanz oder Mittelbarkeit des Erzählens zwischen den Modi "narrative Rede“, „transponierte Rede“ und „dramatische Rede“, die den unterschiedlichen Grad an Vermittlung durch einen Erzähler anzeigen. 
grammatischen Form, dass nach einem solchen Ausflug nie etwas geschehen wird, dass nie etwas anders verlaufen wird. Gerade dem widerspricht aber die Erzählung, wenn nach der Rückkehr plötzlich das Zischen vorhanden sein soll. ${ }^{525}$ Nicht nur in narratologischer, auch in inhaltlicher Hinsicht erweist sich die Iteration als widersprüchlich. Was bleibt, ist eine Irritation, die von der paradoxen zeitlichen Ordnung herrührt, die gleichzeitig Handlung und deren Beschreibung, sowohl singuläre Aktion als auch iterativer Zustand ist. ${ }^{526}$ Es lässt sich hier eine interessante, auf den Erzählvorgang bezogene Wirksamkeit des "gleitenden Paradoxes“, wie es Neumann auf der semantischen Ebene nachgewiesen hat, feststellen: In der Spannung zwischen Iteration und Singulation gibt es ein dauerndes Oszillieren. ${ }^{527}$

In der Überblendung von Iteration und Singulation inszeniert Der Bau eine Mündlichkeit, die kommentarlos zwischen Mimesis und mittelbarer Beobachtung hin und her springen kann. Auch die eigenartige Erinnerungslosigkeit des Textes, wie sie oben herausgearbeitet wurde, erinnert an mündliche Erzählformen, während neben dem offensichtlichen Medium der Schrift die sprachliche Komplexität und die zahlreichen metaphorischen Hinweise auf Schrift und Schriftlichkeit deutlich dagegen sprechen. Jedoch würde auch die Mündlichkeit die Paradoxien im Bau nicht aufheben, da sich diese, wie zu sehen sein wird, auf die Stimme selbst beziehen. ${ }^{528}$

\subsubsection{Probleme der Dauer}

Der Bau weist auch Diskontinuitäten in der Dauer auf. Es finden sich zahlreiche extreme Raffungen und Pausen, in denen die story weiterläuft, jedoch stark verkürzt bzw. gar nicht erzählt wird, was geschieht, also der discourse pausiert. Es sind Momente, in denen der Erzähler schweigt oder etwas anderes erzählt und sich gleichwohl Ereignisse ungesagt vollziehen. Die auffälligste Pause findet sich anschließend an die oben zitierte Episode der Rückkehr in

525 Dies als Dramatisierung des Gewöhnlichen zu beschreiben ist durchaus möglich, vermag jedoch die Paradoxien nicht aufzulösen, die sich daraus ergeben. Vgl. dazu auch Coetzee, der diese Erklärung wenig gewinnbringend findet: „Statt also diese Betonung [auf den Charakter des Iterativen; L. G.] durchweg auszuführen, dramatisiert Kafka manchmal ein typisches Geschehen aus dem iterativen Zyklus [...] und ermöglicht so dem Text für einen Moment den Rückzug in die ungekennzeichnete, nicht-iterative Aktionsart." Coetzee, „Zeit, Tempus und Aktionsart in Kafkas ,Der Bau“', 82. Hervorhebung i. O.

$5_{26}$ Dorrit Cohn versuchte dieses Paradox mit dem Begriff des eternal present zu fassen. Cohn, „Kafka's Eternal Present“.

527 Vgl. Neumanns Bezeichnung der „pseudo-paradoxen“ Formeln bei Kafka: „Kafka verwandelt die Starre des herkömmlichen Paradoxes in ein Gleiten.“ Neumann, „Umkehrung und Ablenkung. Franz Kafkas ,Gleitendes Paradox‘ [1968]“, 371.

528 Siehe Kap. 4.3.2 Die Spuren des Erzählers, S. 239ff. unten. 
den Bau. Das Erzähler-Ich legt sich versuchsweise hin, um zu prüfen, ob es noch immer gut schlafen könne.

Nun aber überkommt mich doch eine gewisse Lässigkeit und auf einem Platz, der zu meinen Lieblingen gehört, rolle ich mich ein wenig zusammen [...], ich will hier nicht schlafen, nur der Lockung gebe ich nach mich hier so einzurichten, wie wenn ich schlafen wollte, nachsehn will ich, ob das hier noch immer so gut gelingt, wie früher. Es gelingt, aber mir gelingt es nicht mich loszureißen, ich bleibe hier in tiefem Schlaf. Ich habe wohl sehr lange geschlafen, erst aus dem letzten von selbst schon sich auflösenden Schlaf werde ich geweckt, der Schlaf muß nun schon sehr leicht sein, denn ein an sich kaum hörbares Zischen weckt mich. Ich verstehe es sofort, das Kleinzeug [...]. (B 6o5f.)

Zunächst sticht der performative Gehalt ins Auge: Die Wiederholung des „aber mir gelingt" bildet abstrakt-mimetisch das Einschlafen ab, so als übertrage sich die zunehmende Schläfrigkeit auf die Sprachverwendung. Auffällig ist die Wendung „ich bleibe hier in tiefem Schlaf", bezeichnet sie doch zum einen mit dem deiktischen „hier“ den Ort und die Gegenwart des Erzählens, zum anderen benennt sie den Zustand des Schlafes eben dieses erzählenden Ich. Wenn das Ich aber erzählt, kann es nicht gleichzeitig schlafen. Da im Singulativ formuliert, entsteht daraus eine paradoxe Situation, in der der Erzähler gleichzeitig erzählt und schläft, was die Grenzen des autodiegetischen Modells sprengt. ${ }^{529}$ Die der Erzählung zugrunde liegende Ordnung ist, wie hier deutlich zu sehen ist, eine prekäre Ordnung.

529 Es sei denn, man würde aufgrund der formalen Unmöglichkeit der gleichzeitigen Singulation und Iteration darauf schließen, dass es sich beim zweiten Teil der Erzählung um einen Traum handelt, aus dem der Erzähler nicht mehr aufwacht. Aber diese Interpretation ist Spekulation. Zudem übersieht diese Lektüre, dass die zeitlichen Aporien den Text regelrecht grundieren und konstitutiv für das Erzählen sind.

Um das traumartige Schreiben Kafkas zu fassen, wurde vielfach dessen Wendung des "traumhaften innern Lebens“ zitiert. Vgl. Kafka, Tagebücher, 546. Kafka visiert mit dieser Beschreibung nicht die Darstellung des Traums an, sondern die adäquate Form des Erzählens für dieses innere Leben. Vgl. die einflussreiche ältere, biographisch ausgerichtete Studie: Friedrich Beißner, „Kafkas Darstellung des ,traumhaften innern Lebens [1968]“, in Der Erzähler Franz Kafka und andere Vorträge. Mit einer Einführung von Werner Keller (Frankfurt am Main: Suhrkamp, 1983), 123-149.

Vgl. auch Joseph Vogl, der bezüglich den Erzählanfängen des Erwachens aus der Verwandlung und dem Process schreibt: „Man begegnet niemandem: das Erwachen wird referiert, während gleichzeitig der Bericht mit dem Erwachen beginnt, und beide, berichtendes und erwachendes Ich, wiederholen sich wechselseitig, kommen einander immer zuvor und halten die Spur eines Augenblicks fest, an dem Bewußtsein und Bewußtlosigkeit aneinanderstoßen.“ Joseph Vogl, „Vierte Person. Kafkas Erzählstimme“, DVJS. Deutsche Vierteljahrsschrift für Literaturwissenschaft und Geistesgeschichte 68, Nr. 4 (1994): $75^{6 .}$ 
Auch das Erwachen wird sprachlich durch die mehrfache Nennung als stufenweiser Prozess nachgebildet. Befremdend ist die Zeitlichkeit: Der Satz "Ich habe wohl sehr lange geschlafen“ stellt eine Reflexion über die Dauer des Schlafes dar, nimmt also eine Distanz zum Vergangenen ein. Dies steht in einer Spannung zum performativen Gehalt der anschließenden Sätze, die mit der mehrfachen Nennung des Weckprozesses ein Aufwachen und zunehmendes Verflüchtigen der Schläfrigkeit darstellen. Plötzlich („ich verstehe sofort“) ist das Erzähler-Ich schließlich wach und ergibt sich wieder seinen Reflexionen. ${ }^{530}$

Das Erzähler-Ich macht sich anschließend auf die Suche nach möglichen Quellen und Ursachen des Zischens. Dies wird mit extremen Raffungen, Pausen und iterativen Sequenzen, die die erzählte Zeit sprunghaft und rasch durchlaufen, dargestellt.

Nur zum Ausruhn, zum Selbstbesinnen mache ich häufig diese Versuche, horche angestrengt und bin glücklich nichts zu hören. (B 612)

Nun habe ich schon viele Grabungen gemacht, um eines von ihnen [den fremden Tieren; L. G.] zu fassen, aber ich finde keines. (B 614)

[Ö]fters bin ich schon für ein Weilchen in irgendeinem Loch bei der Arbeit eingeschlafen, die eine Pfote eingekrallt oben in der Erde, von der ich im letzten Halbschlaf ein Stück niederreißen wollte. (B 614)

Und noch weitere unnütze Entdeckungen mache ich. Manchmal scheint es mir, als habe das Geräusch aufgehört [...]. (B 618)

Diese Stellen machen deutlich, dass vieles von dem, was der Protagonist unternimmt, gar nicht geschildert wird. Die Informationsvergabe ist gemäß dem Rahmen der (pseudo-)autodiegetischen Erzählung gänzlich vom Protagonisten und Erzähler abhängig, wie bereits an den Ungereimtheiten bezüglich der Jagd sowie des Eintritts und Austritts in und aus dem Bau deutlich wurde. Die Ungereimtheiten des unzuverlässigen Erzählers und die Abhängigkeit des Lesers von diesem haben eine Ordnung zur Folge, die immer wieder neu konturiert

530 Es ist diese Form des Erzählens, die zwischen Distanz, Reflexion und der Unmittelbarkeit interner Fokalisierung bis hin zur erlebten Rede changiert, die Kafkas Erzählen so faszinierend und irritierend macht und für die literaturwissenschaftliche Beschreibung eine Herausforderung darstellt. Diese Vielfalt der Perspektivierung scheint mir auch die Grundlage der Debatte über Friedrich Beißners Begriff der „Einsinnigkeit“ von Kafkas Erzählen zu sein, der die interne Fokalisierung betont, während andere die durchaus vorhandene Distanz nachwiesen. Vgl. Friedrich Beißner, „Der Erzähler Franz Kafka [1951]“, in Der Erzähler Franz Kafka und andere Vorträge. Mit einer Einführung von Werner Keller (Frankfurt am Main: Suhrkamp, 1983), 19-54; Winfried Kudszus, „Erzählhaltung und Zeitverschiebung in Kafkas ,Prozeß' und ,Schloß'“, Deutsche Vierteljahrsschrift für Literaturwissenschaft und Geistesgeschichte 38, Nr. 2 (1964): 192-207. Vgl. auch Constanze Busse, Kafkas deutendes Erzählen. Perspektive und Erzählvorgang in Franz Kafkas Roman „Das Schloss" (Münster: LIT Verlag, 2001). 
wird. Hinzu kommt die oben bereits herausgearbeitete Sprengung des autodiegetischen Rahmens als verlässliche, auf Logik rekurrierende Grundlage der Erzählung.

Die Raffungen und Pausen erzeugen den Eindruck einer diskontinuierlichen Zeit, welche eine nicht nur psychologische Erklärung dafür anbietet, dass sich der Erzähler plötzlich als alt empfindet. Ohne dass das Vergehen der Zeit dargestellt würde, heißt es zunächst, der Erzähler befinde sich auf dem „Höhepunkt“ (B 577) seines Lebens, nur um gegen Ende alt geworden zu sein: „Aber wie alt ich auch bin, es scheint mir, daß ich recht gern noch älter wäre als ich bin, so alt, daß ich mich gar nicht mehr erheben könnte von meinem Ruhelager unter dem Moos." (B 628f.) Einer solchen Zeit liegt kein verbindliches Maß zugrunde, das eine einheitliche Ordnung garantierte. Stattdessen ist auch die Zeitlichkeit abhängig vom paradoxen Erzählen einer widersprüchlichen und unzuverlässigen Figur, einer körper- und ortlosen Stimme.

\subsubsection{Prekäre Zeitordnung}

Es ist also bezüglich der Zeitstruktur festzuhalten, dass in der Erzählung mit der konventionellen Erzählordnung, die auf einer Chronologie der Ereignisse und auf der Logik der motivierten und kontinuierlichen Verknüpfung der Erzählelemente beruht, gebrochen wird. Der Bau hat, wie Dorrit Cohn formuliert, eine „illogical temporal structure“.531 John Coetzee spricht von einer Zeit, die „labyrinthisch“532 und „diskontinuierlich“533 ist. Diese unberechenbare Zeitstruktur subvertiert fundamentale Ordnungskriterien der Narratologie und der rationalen Weltbetrachtung. ${ }^{534}$ Gleichzeitig erzeugt der Text mit dieser Darstellung des Zeitgefüges ein zeitliches Empfinden, das dem

531 Cohn, Transparent Minds. Narrative Modes for Presenting Consciousness in Fiction, 197. Die Narratologin Dorrit Cohn hat in ihrer einflussreichen Studie zur Darstellung des Bewusstseins in der Literatur diese Zeitstruktur präzise herausgearbeitet.

532 Coetzee, „Zeit, Tempus und Aktionsart in Kafkas ,Der Bau““, 84.

533 Coetzee, 95 .

534 Auch Michael Niehaus stellt die Unvereinbarkeit der Frequenzen fest. In der „Subjektspaltung" in einen beschreibenden (iterativen) und einen handelnden (singulativen) Part sieht er ein Indiz dafür, dass es sich um einen Protagonisten handelt, der "sein Verhalten nicht durch auf Einsicht beruhende Willensakte zu ändern imstande ist und daher in einer Wiederholungsschleife gefangen bleibt. Man kann auch sagen, wir beobachten ihn auf einer Ebene, auf der er sich nicht vom Tier unterscheidet." Michael Niehaus, „Iterativität bei Kafka. Vorläufige Bemerkungen“, in Kafkas narrative Verfahren, hg. von Harald Neumeyer und Wilko Steffens, Forschungen der Deutschen Kafka-Gesellschaft 3 (Würzburg: Königshausen \& Neumann, 2015), 124. Hervorhebung i. O. Mit dem zweiten Teil jedoch, der im Singulativ erzählt wird, erweise sich die „Unmöglichkeit des Wohnens [...] - die Gewohnheit, in der wir uns eingerichtet haben." Niehaus, 127. Hervorhebung i. O. 
phänomenologischen Erleben der Zeit in der Lebenswelt nicht selten näher kommen mag, als dies eine regelmäßige Zeitgestaltung bewirken kann.

Wahrnehmen und Empfinden werden durch die Überblendung von singulativem und iterativem Erzählen in einem ambivalenten Modus von Einzigartigkeit und Wiederholung erzählt. Die Wiederholung wird vom Erzähler-Ich dennoch jedes Mal mit großer Intensität als Neuheit erlebt. Es ist, als würde im Bau gleichzeitig aus zwei Perspektiven erzählt werden, aus einer, die die Ereignisse neu, intensiv und singulativ erfährt und einer, die das Leben reflektierend als ständige Iteration wahrnimmt. Es bleibt eine irritierend resistente Ambivalenz, die aufgrund ihrer konstitutiven Bedeutung für den Bau als prekäres Erzählen qualifiziert.

\section{3 „Aber im übrigen, was ist denn geschehn?“ Problematik des Ereignisses}

Die Auseinandersetzung mit dem iterativen und singulativen Erzählen problematisiert auch die Ereignishaftigkeit der Erzählung. Dem Ereignis ist in der narratologischen Theoriebildung in der Regel die singulative Erzählweise vorbehalten, während der Iterativ einen Zustand erzeugt. ${ }^{535}$ Diese Spannung hinsichtlich der Ereignishaftigkeit scheint Der Bau explizit hervorzuheben, wenn der Erzähler in Bezug auf das Zischen fragt: „Aber im übrigen, was ist denn geschehn?“ (B 612)

\subsection{1 „Was ist es denn? [...] [E] in Nichts“. Ein unbestimmtes Geräusch}

Die Frage formuliert den Zweifel des Ich-Erzählers an der tatsächlichen Existenz des Zischens. Fände er eine Ursache des Geräuschs, eine Erklärung für das Zischen, wäre auch dessen Vorhandensein durch die Kausalitätsrelation bestätigt. Der Text verweigert sich einer solchen Lösung, die Wahrnehmung des Zischens wird stets in einem unbestimmten Zustand zwischen Einbildung und Wirklichkeit belassen. Die Beschreibungen des Geräuschs

535 Wolf Schmid, wie schon zitiert, nennt fünf Bedingungen, die eine Zustandsveränderung erfüllen muss, um als Ereignis zu gelten: Relevanz, Imprädikabilität, Konsekutivität (gemeint sind damit die Konsequenzen der Figurenhandlungen, die gegeben sein müssen), Irreversibilität und Non-Iterativität. Schmid, Elemente der Narratologie, 14-19. Vgl. auch Hühn, der einen Ereignisbegriff im Sinn von Jurij Lotman als Überschreiten einer semantischen Grenze abstrakt definiert und einen anderen formal im Sinn Schmids als irreversible und intentionale Zustandsveränderung definiert. Hühn, „Event and Eventfulness". 
sind widersprüchlich. Einmal scheint es durchgängig zu sein, an anderen Stellen wird es immer wieder von langen Pausen unterbrochen.

Manchmal scheint es mir, als habe das Geräusch aufgehört, es macht ja lange Pausen, manchmal überhört man ein solches Zischen, allzu sehr klopft das eigene Blut im Ohr, dann schließen sich zwei Pausen zu einer zusammen und ein Weilchen lang glaubt man, das Zischen sei für immer zuende. (B 618)

\section{Diese Beschreibung erzeugt weitere Unsicherheit bezüglich des Status des} Geräuschs. Wenn das Blut so sehr „im Ohr“ klopft, dass es das Zischen übertönt, das Ich also zahlreiche eigene Geräusche produziert, dann könnte auch das Zischen vom Erzähler-Ich selbst stammen. ${ }^{536}$ Implizit wird so weitere Ambivalenz bezüglich der Art und des Vorhandenseins des Geräuschs erzeugt.

536 Uwe Steiner zeigt in seiner Kulturgeschichte des Tinnitus auf, wie Der Bau „ein Schlüsseltext für die literarische Beobachtung des Tinnitus" darstellt. Uwe C. Steiner, Ohrenrausch und Götterstimmen. Eine Kulturgeschichte des Tinnitus (Paderborn: Wilhelm Fink, 2012), 161. Steiner stellt fest, dass Geräusche und Horchen im Werk Kafkas weit verbreitet sind. Er betont die konstruktivistische Seite des Tinnitus als „Metapher für Kultur im Ganzen“: „Das Ohrengeräusch ist nicht einfach nur die kausal bedingte Reaktion auf das zivilisatorische Lärmtrauma. Es vollzieht vielmehr die allgemeine Geräuschproduktion eigentätig nach. Nur ist diese Eigentätigkeit nicht mehr, wie zu Zeiten der Subjektphilosophie, ein Privileg des Subjekts. Lärm ist [...] autopoietisch.“ Steiner, 155 f. So lässt sich anhand des Ohrengeräuschs mitunter die Verschiebung in der Moderne nachzeichnen, die dem Subjekt seine autonome Position streitig macht. Bezogen auf den Proceß zeigt Steiner anhand der Geräusch-Analyse plausibel auf, wie sich im Text eine Umkehrung von Innen und Außen manifestiert: Als K. die Gerichtskanzleien aufsucht und im Wartezimmer wartet, widerfährt ihm, wie Steiner argumentiert, ein Anfall von Tinnitus. Steiner, 137. Dieses „Leiden markiert [...] das Scheitern der abendländischen Vorstellung von Subjektivität: Monadisch in sich verkapselt, ganz dem Geräusch hörig, das er selbst produziert, verfällt er einer puren Äußerlichkeit. Hegel hatte das Ohr noch als Organ der Innerlichkeit bezeichnet. Und dort, im Inneren sozusagen der Innerlichkeit, ertönt nun ein so erschütterndes wie verlockendes Drama der Äußerlichkeit." Steiner, 139f. Das Außen wird also - systemtheoretisch gesprochen - mittels re-entry nachgebildet. Diese Darstellung ist symptomatisch für die Epoche: Kafka „macht im subjektiven Ohrgeräusch ein diskursives, ein mediales, ein Problem der Kommunikation aus, der zu folgen K. zeitweise nicht in der Lage ist. [...] Er beschwört ja weniger die materielle, als vielmehr die diskursive Produktion herauf, weniger das maschinelle, als vielmehr das mediale Lärmparadigma." Uwe C. Steiner, „Signalverarbeitung und letzte Dinge. Tinnitus als Epochenkrankheit in der Literatur von Kafka bis zur Gegenwart“, in Epochen/Krankheiten. Konstellationen von Literatur und Pathologie, hg. von Frank Degler und Christian Kohlroß (St. Ingbert: Röhrig, 2006), 216. Vgl. dazu auch Jürgen Daiber, Franz Kafka und der Lärm. Klanglandschaften der frühen Moderne (Münster: Mentis Verlag, 2015).

In der Sekundärliteratur ist es ein wiederkehrender Topos, dass bei der Interpretation dieses Zischens der „biographische[] Kontext [...], also Kafkas weit fortgeschrittene Lungenkrankheit und das damit verbundene pfeifende Atemgeräusch“ nicht außer Acht 
Der Erzähler kann nicht sagen, was es ist: „Was ist es denn? Ein leichtes Zischen, in langen Pausen nur hörbar, ein Nichts“ (B 615). Das Geräusch ist nur mit größter Konzentration wahrzunehmen: „Und wieviel Zeit, wieviel Anspannung erfordert dieses lange Horchen auf das pausenweise Geräusch." (B 612) Es ist außerordentlich leise und nur phasenweise zu hören. Diese Beschreibung erinnert wiederum an die Bemerkung des Erzählers vor dem Schlaf, dass von Zeit zu Zeit kleine Tiere zu hören seien. Es ist also durchaus möglich, dass sich tatsächlich nichts Spezifisches ereignet hat, sondern nur die Paranoia des Erzählers eine Veränderung hypostasiert, wie diese schon Ursache für die Umverteilung der Vorräte war. ${ }^{537}$ Mit der zunehmenden Verunsicherung des Erzählers wird der Leser immer skeptischer gegenüber dem Geschilderten.538 Die Frage, ob denn überhaupt ein Ereignis stattgefunden hat, bleibt virulent. Gegen Ende des Textes scheint das Geräusch zunächst intensiver zu werden:

[A]llzu sehr in Anspruch genommen bin ich von dem Zischen in meinen Wänden. Bin ich davon in Anspruch genommen? Es wird stärker, es kommt näher [...]. (B 621f.)

Und jetzt wird nun das Geräusch doch stärker, die Kreise also enger. (B 624)

gelassen werden dürfe. So wäre „der innere Feind leicht als nahender Tod zu identifizieren.“ Engel, „Kafka und die moderne Welt“, 51of. Vgl. auch Maché, „The Noise in the Burrow".

Auch Reiner Stach betont den biographischen Bezug im Bau in seiner dreibändigen Biographie zu Kafka: „Das Geräusch des eigenen, allmählich kürzer werdenden Atems, dieses Lebenszeichen, das immer schon da war, auf das aber erst der Kranke angstvoll horcht, dieses Geräusch ist der Gegner. Kafka hat auch diese Metapher nicht erfunden, er hat sie vorgefunden, und seinem Text kommt am nächsten, wer sie wörtlich nimmt." Reiner Stach, Kafka. Die Jahre der Erkenntnis (Frankfurt am Main: Fischer, 2008), 592. Hervorhebung i. O.

$\mathrm{Ob}$ das Zischen existiert und was es bedeutet, ob es als Metapher des nahenden Todes, als Bild existenzieller Angst fungiert, ob es als Tinnitus oder pfeifendes Atmen verstanden werden kann und in Bezug zu Kafkas Lungenkrankheit zu setzen oder mit Kittler als pfeifende Granaten in Schützengräben zu lesen ist, muss offen bleiben. Zentral ist jedoch, wie der Text diese Vielfalt an Semantiken aufbietet, lenkt, widerlegt und wie die Ambivalenz diesbezüglich konstitutiv für den Text selbst wird. In diesem Sinn wird das Zischen zu einem Rauschen, in welchem die zahlreichen Erklärungen in der Ambivalenz verschwimmen.

537 Siehe Kap. 4.1.3 Langfristige Planung und spontane Neuordnungen, S. 216ff. oben.

538 Vgl. dazu Gelus: „Granted, the animal participates to a great extent in creating the conditions of his world - the army of enemies that he describes approaches under the banner that is the law of his life: not that of reality, but that of possible realities [...]. And his utterances are too muddled and jumbled to be considered reliabale [sic] indices of the world around him." Marjorie Gelus, „Notes on Kafka's ,Der Bau'. Problems with Reality“, Colloquia Germanica 15, Nr. 1/2 (1982): 106. 
Aber auch diese Beobachtung wird relativiert. Der Erzähler hält insgesamt viermal fest, dass das Geräusch nicht zugenommen, dass sich nichts verändert hat. ${ }^{59}$ Beim Wiedereintritt in den Bau bemerkt der Erzähler: „Alles ist unverändert, kein größeres Unglück scheint geschehen zu sein“ (B 604). Später stellt der Erzähler fest, dass auch unter dem Eingang, wo das Zischen nicht zu hören ist, alles beim Alten blieb: „[H]ier hat sich nichts verändert" (B 621). Ein drittes Mal konstatiert er nach einem Hin und Her, ob das Zischen lauter oder leiser wurde: „[D] as Zischen ist gleich geblieben, nichts hat sich geändert.“ (B 629) Und letztlich wiederholt er dasselbe im abgebrochenen Schlusssatz: „aber alles blieb unverändert" (B 632).540

Fortlaufend wird im Text die Frage verhandelt, ob ein Ereignis stattgefunden hat oder nicht, was Ursache und was Wirkung sein könnte. Am Ende entscheiden nicht die Logik oder die Wahrscheinlichkeit über die gültige Erklärung, sondern das Gefühl des Erzählers. Sein Instinkt bezüglich des Zischens beschreibt er am Ende folgendermaßen:

Aber was helfen alle Mahnungen zur Ruhe, die Einbildungskraft will nicht stillstehn und ich halte tatsächlich dabei zu glauben - es ist zwecklos, sich das selbst abzuläugnen -, das Zischen stamme von einem Tier undzwar nicht von vielen und kleinen sondern von einem einzigen Großen. (B 622f.)

Es ist bezeichnend, dass - neben den schon diskutierten Fällen der Gier und der Arbeitsfreude - auch die „Einbildungskraft" sich vom Erzähler abspaltet und Selbstständigkeit erlangt. Wie die „häufige Beschäftigung mit Verteidigungsvorbereitungen" (B 582) die Panik des Planens mit sich bringt, so ist es hier die Einbildungskraft, die die schlimmste Möglichkeit zur Tatsache erklärt.

Deutlich und wiederholt weist der Text also auf Unstimmigkeiten bezüglich des Vorhandenseins des Geräuschs hin. Dies leistet den Fragen nach der Ereignishaftigkeit und der Unterwanderung von Kausalität Vorschub. ${ }^{541}$ In

539 Vgl. dazu Henel, der die dreimalige Wiederholung dieser Aussage als „drei Stufen im Bewußtsein des Tieres“ deutet: Von der Bewertung des Baus als sicheren "Ort der Stille“, zur Umkehrung der Verhältnisse und schließlich zur unveränderten „Ratlosigkeit des Tieres“. Henel, „Das Ende von Kafkas ,Der Bau““, $19 f$.

540 Daneben bleibt auch anderes unverändert. Der Erzähler berichtet: „[Ich] lausche in die Stille, die hier unverändert herrscht bei Tag und Nacht“ (B 580); und: „Ich komme gar nicht dem Ort des Geräusches näher, immer klingt es unverändert dünn in regelmäßigen Pausen" (B 607).

541 Bei Franz Kafka ist diese Thematisierung der Kausalität bis in die Satzstrukturen festzustellen. Gut zeigen lässt sich dies an seinen unvollständigen Wenn-dann-Konstruktionen. Häufig wird bloß der Konditional mit „wenn“ einfgeführt, ohne darauf die Folge („dann“) zu erwähnen. Die Kausalität bleibt im Vollzug stecken. In der Kurzprosa ist dies insbesondere im Text Wunsch, Indianer zu werden gut nachzuvollziehen. Der Text besteht 
dieser Hinsicht ist Der Bau auch eine Darstellung seiner eigenen narrativen Verfahren: Er macht eine Konzeption von Ordnung sichtbar, die ihren Gegenstand im Akt des Ordnens erzeugt.

\subsubsection{Die Spuren des Erzählers}

In der Erzählsituation wird der Erzähler in der Regel, so verborgen er auch sein mag, greifbar. Wenn auch der Status des Erzählten prekär ist, so ist doch deutlich, dass etwas erzählt wird und dieses Sprechen in einem Jetzt stattfindet. Zunächst stellt sich eine unproblematisch erscheinende Erzählsituation dar: „Ich lebe im innersten meines Baues in Frieden und inzwischen bohrt sich langsam und still der Gegner von irgendwoher an mich heran, ich will nicht sagen, daß er bessern Spürsinn hat als ich [...].“ (B 577, Hervorhebung L. G.) Die Wendung „ich will nicht sagen“ referiert auf den Erzählakt, während die anderen Teile in iterativer Erzählweise die Lebensumstände beschreiben. Zwar gibt es an mehreren Stellen Hinweise, wo der Erzähler sich zum Zeitpunkt des Erzählakts befindet und von wo aus er erzählt, jedoch ist die Ich-jetzt-hier-Origo nicht gesichert und bleibt fragmentarisch: „Ich liege hier auf einem allseits gesicherten Platz, [...] und zwischen Hindämmern und bewußtlosem Schlaf vergehn mir die Stunden, die ich nach meinem Belieben dafür wähle." (B 580) Der Erzähler liegt im Dämmerzustand auf einem der vielen Plätze und rekapituliert sein Leben aus einem Zustand heraus, wie es auch der Eingangssatz - „Ich habe den Bau eingerichtet und er scheint wohlgelungen." (B 576) - suggeriert. Es wird eine nachvollziehbare Erzählsituation gebildet, die durchaus eine Erzählerillusion erzeugt. ${ }^{542}$ Reflexe auf das Genre der Memoiren, der Lebensberichte und der extradiegetischen Erzählung sind deutlich. Aus dieser Position heraus bestünde die Möglichkeit für den Erzähler, die iterativen Elemente zusammenzufassen, einen Rückblick zu halten, bis er wieder aufbräche und sich daraus eine neue Erzählsituation ergeben könnte, von der aus er erzählen könnte.

Jedoch wird diese Erzählsituation sogleich unterwandert. Der abschließende Relativnebensatz im obigen Zitat weist auch auf der Ebene des

aus einer Kaskade von „Wenn“-Anfängen, die im Verlauf des Textes ohne Ergänzung aufgehoben werden. So wird statt der Kausalität die Performanz unterstrichen. In Bezug auf Der Bau schreibt Oliver Simons: „In seinen [Kafkas] Aufzeichnungen zum Bau etwa gibt es zwar zahlreiche Wenn-Dann-Sätze, noch häufiger aber wiederholt der Erzähler ein Wenn, ohne ein Dann folgen zu lassen. Ein Wenn wird $5_{1}$ Mal wiederholt, das Dann lediglich 45 Mal. Gerade daran aber lässt sich ermessen, inwiefern der Bau eine systematische Erkundung eines logischen und syntaktischen Verfahrens ist, einer Schluss- und Schreibweise.“ Oliver Simons, „Diagrammatik - Kafka mit Deleuze“, in Die Räume der Literatur. Exemplarische Zugänge zu Kafkas Erzählung „Der Bau“, hg. von Dorit Müller und Julia Weber (Berlin, Boston: De Gruyter, 2013), 108.

542 Siehe Kap. 3.3.1 Zum Begriff der Performanz in der Narratologie, S. 168ff. oben. 
Erzählens auf Iteration hin. Der Erzähler ,wählt' die Stunden des Dämmerns „nach [s] einem Belieben“. Dies betont den Wiederholungscharakter und steht im Widerspruch zur Singulation des Erzählvorgangs. Diese scheinbar unverfängliche Stelle veranschaulicht schon die Komplexität der überlagerten Zeiten in Der Bau. Es wird ein Naturalisierungsangebot für die Erzählstimme gemacht, das im nächsten Atemzug desavouiert wird. ${ }^{543}$ Zugespitzt ergibt sich in der Konsequenz, dass es sich hier um einen eigentlich unmöglichen Erzähler handelt. ${ }^{544}$ Auch die Erzählsituation ist vor der Überblendung iterativer und singulativer Erzählfrequenzen nicht gefeit. Der scheinbare Dämmerzustand der Mußestunden kann keineswegs als Schreibszene von Memoiren naturalisiert werden. ${ }^{545}$

Eine ähnlich ambivalente Etablierung einer Erzählszene findet sich nach der bereits erwähnten Beschreibung der Umverteilung der Vorräte auf verschiedene Plätze: „Wie es auch sei, ich muß mich mit dem einen [Burgplatz] begnügen, die kleinen Plätze können ihn unmöglich ersetzen und so fange ich dann, wenn diese Anschauung in mir gereift ist, wieder an alles aus den kleinen Plätzen zum Burgplatz zurückzuschleppen." (B 585) Hier liegt die Spannung zwischen der Erkenntnis als einmaligem Ereignis und der iterativen Handlung der Umverteilung der Vorräte. Mit der Wendung „[w]ie es auch sei, ich muß mich mit dem einen [Burgplatz] begnügen" wird Unmittelbarkeit erzeugt: Die Erkenntnis ist gewonnen, der Entscheid gefallen, sich damit zu begnügen. Dagegen erzeugt das „dann“ und „wieder“ den Eindruck von Wiederholung: Es läuft immer so ab, dass zunächst diese "Anschauung“ wieder ,reifen' muss, um dann zu jener Erkenntnis zu gelangen. ${ }^{546}$ Dies ist paradigmatisch für das unsichere Erinnerungsvermögen des Textes: Wissen ist wechselhaft, unsicher und abhängig von Kontext, Zeit und Verfassung des Erinnernden.

In der Szene des Austritts aus dem Bau, in der die Überblendung iterativer und singulativer Erzählweise, wie gezeigt, sehr prägnant ist, werden durch die

543 Vgl. Cullers Konzept der naturalization: Jonathan Culler, Structuralist Poetics. Structuralism, Linguistics and the Study of Literature (London: Routledge \& Kegan Paul, 1975). Für die Debatte mit Monika Fludernik und ihrem Term narrativization siehe Kap. 5.2 ,Natural ${ }^{\star}$ Narratology (Fludernik), S. 253ff.; Kap. 5.3 Unnatural Narratology, S. 257ff. unten.

544 Vgl. auch Krogh Hansen, „First Person, Present Tense. Authorial Presence and Unreliable Narration in Simultaneous Narration“.

545 So auch Dorrit Cohns These zu Kafkas Ein Landarzt: „The classic image of the old man sitting at his desk composing his memoirs has been radically modified: Kafka's hero is not an old man at peace; he will, most likely, not die in bed, it is indeed questionable whether he will die at all. Suspended in a hopeless and unbearable limbo, between life and death, his final situation is projected into an unending future“. Cohn, „Kafka's Eternal Present“, 146.

546 Vgl. Coetzee, „Zeit, Tempus und Aktionsart in Kafkas ,Der Bau““. 
deiktischen Ausdrücke die Bewegungen des Erzähler-Ich deutlich, ohne dass sie explizit als Handlung erzählt würden. Während der Erzähler sich außerhalb des Baus befindet, ist das einzige, was als Handlung greifbar wird, jeweils die indirekt vermittelten Änderungen der Erzählerposition. Alle eigentlichen Handlungen, wie das Jagen, das Beobachten des Eingangs, das Graben eines Beobachtungslochs werden nicht oder nur in stark geraffter Form erzählt.547 Besonders deutlich ist dies an folgender Stelle, an der der Erzähler von der mangelnden Sicherheit des Baus sowie, in der Konsequenz, seinem Versagen als Baumeister spricht: „Es ist sehr schmerzlich sich das einzugestehn, aber es muß geschehn, gerade angesichts des Eingangs dort, der sich jetzt gegen mich den Erbauer und Besitzer abschließt, ja förmlich verkrampft." (B 6oo, Hervorhebung L. G.) Die Ich-jetzt-hier-Origo des Erzählers ist deutlich benannt: Die deiktischen Ausdrücke "dort“ und "jetzt“ ermöglichen eine sichere räumliche und zeitliche Positionierung des Erzählers. Obwohl im präsentischen Singulativ erzählt, werden beim Wiedereintritt in den Bau fortlaufend deiktische Ausdrücke verwendet, welche die ausgesparten Handlungselemente in der Fortbewegung des Erzählers markieren: „Ich gehe deshalb den Gang abwärts bis zum Burgplatz und beginne dort zu horchen. Sonderbar, das gleiche Geräusch auch hier." (B 6o9, Hervorhebung L. G.) Ist der Erzähler im ersten Satz noch nicht beim Burgplatz („dort“), so ist er im zweiten da („hier“). „Ich horche jetzt die Wände des Burgplatzes ab“ (B 612), heißt es wenig später. Dazwischen wird eine Reflexion über einen der "Lieblingspläne“ (B 611) angestellt sowie über die Ursache des Geräuschs spekuliert, jedoch keine Handlung beschrieben. Ohne es zu erwähnen, ist der Erzähler vom bloßen Horchen zum Graben übergegangen, von der Reflexion zur Tat. Das Graben und Suchen nach dem Geräusch findet ebenfalls nur als Reflexion Erwähnung: „Aber alles dieses Schöne [der "Lieblingsplan“] besteht nun eben nicht und ich muß an meine Arbeit [...]. Ich brauche freilich, wie sich immer mehr herausstellt alle meine Kräfte zu dieser Arbeit, die zuerst eine ganz geringfügige schien." (B 612) Dann heißt es unvermittelt: „Nun habe ich schon viele Grabungen gemacht“ (B 614). Deutlich tritt hervor, dass der discourse keineswegs durchgängig das Geschehen abbildet.

547 Das Beobachtungsloch stellt für eine Lektüre, die die Iteration betont, eine Herausforderung dar. Denn wenn die Ausflüge immer gleich abliefen, was in der iterativen Form der Fall wäre, müsste konsequenterweise der Boden rund um den Eingang mit solchen Löchern übersät sein. Vgl.: „Ich grabe, natürlich in genügender Entfernung vom wirklichen Eingang, einen Versuchsgraben, er ist nicht länger als ich selbst bin und auch von einer Moosdecke abgeschlossen. Ich krieche in den Graben, decke ihn hinter mir zu [...].“ (B 594) 
Schließlich steigt der Erzähler auf der Suche nach Stille den Gang vom Burgplatz hinauf bis unter das Moos, findet dort aber keine Ruhe und steigt wieder hinab zum Burgplatz: „Auf dem Burgplatz wähle ich ein schönes Stück enthäuteten roten Fleisches aus und verkrieche mich damit in einen der Erdhaufen“ (B 630). Dieser Erdhaufen bleibt dann der Aufenthaltsort des Erzählers bis zum Abbruch der Erzählung. Darin spiegelt sich die Erzählszene des Anfangs. Zugleich findet damit eine eigentümliche, gleichsam umgekehrte Verwirklichung jenes Lieblingsplans statt, der um den Burgplatz eine zweite Höhle gebaut hätte: Im Erdhaufen innerhalb der Höhle sucht der Erzähler Schutz.

Es zeigt sich also, dass die Trennung in einen iterativen ersten und einen singulativen zweiten Teil des Baus fragwürdig ist. Zwar lässt sich aus den impliziten Bewegungen und Handlungen des Erzählers eine gewisse Verlässlichkeit der story herstellen. Dennoch bleiben die Bewegungen lückenhaft, vieles muss erschlossen werden, manches bleibt widersprüchlich. Handlungen sind hochgradig unbestimmt und unsicher. Das prekäre Erzählen Kafkas verfügt über einen zwischen Ortlosigkeit und Anbindung, zwischen Iteration und Singulation oszillierenden Ursprung.

\subsection{Die Performanz des Baus}

Durch die Verunsicherung der Ordnung von story und discourse wird in Der Bau der Fokus auf den Akt des Erzählens selbst gelegt. ${ }^{548}$ Den Status der Ereignishaftigkeit befragend, verweist Der Bau schließlich auf sich selbst. Gerade die analysierten Stellen simultanen Erzählens, in denen der Erzählakt und das erzählte Geschehen gleichzeitig stattfinden, machen dies besonders deutlich:

Es [das Zischen] wird stärker, es kommt näher, ich aber schlängele mich durch das Labyrint und lagere mich hier oben unter dem Moos, es ist ja fast, als überließe ich dem Zischer schon das Haus, zufrieden wenn ich nur hier oben ein wenig Ruhe habe. Dem Zischer? Habe ich etwa eine neue bestimmte Meinung über die Ursache des Geräusches? Das Geräusch stammt doch wohl von den Rinnen, welche das Kleinzeug gräbt? Ist das nicht meine bestimmte Meinung? (B 621f.)

548 Vgl. dazu auch, hier auf den Schreibakt übertragen, Alexander Honold: „Die fortlaufende Entstellung und Verfremdung des Dargestellten ist ein Effekt des Darstellens; ein Indiz dafür, dass Darstellung stattfindet.“ Alexander Honold, „Kafkas Trickster. Zum Auftritt des Fremden in der Schrift", in Kafkas Institutionen, hg. von Oliver Simons und Arne Höcker (Bielefeld: transcript, 2007), 308. Zur theoretischen Grundlage siehe Kap. 3.3.1 Zum Begriff der Performanz in der Narratologie, S. 168ff. oben. 
Die ersten Teilsätze sind noch im retrospektiven Iterativ zu lesen - das Zischen kommt Stück für Stück näher, das Ich schlängelt sich davon --, dann macht die zweite Hälfte des Satzes die Erzählsituation deutlich: Der Erzähler befindet sich jetzt unter dem Moos („hier oben“) und spricht zu sich selbst. Dabei scheint er sich selbst zu überraschen, indem er plötzlich bekennt, er glaube, das Zischen stamme von einem einzelnen Tier, einem „einzigen Großen“ (B 623). Erzählte Zeit und Erzählzeit decken sich in diesem Moment: Unter dem Moos liegend rekapituliert der Erzähler das Geschehen. Das Wiedererzählen wird dabei zu einem simultanen Erzählen, das im zweiten Satz metanarrativ wird. Im Versuch, das Zischen und die eigene Reaktion darauf zu begreifen, also Ordnung in die Darstellung des Geschehenen zu bringen, wird der Erzähler gleichsam von seiner eigenen Rede überrumpelt („Ist dies nicht meine bestimmte Meinung?").

Paradoxerweise wird durch die performative Erzählweise eine neue Form von Ordnung erzeugt. Fällt der narrative Rahmen einer Erzählung durch die Erzeugung einer performativen Sprechsituation weg, so kann aus dieser Position grundsätzlich alles gesagt werden, auch in jeder Form. Als Inszenierungen des Erzählens sind paradoxe Sprechsituationen ebenso möglich wie Selbstwidersprüche. Paradoxe Strukturen sind keine Systemfehler mehr, sondern können als Effekte des Sprechakts eines Erzählers verstanden werden. Das Sprechen kann durchaus konventionelle Züge annehmen, was im Bau auch tatsächlich geschieht, wenn plötzlich wieder deutliche Vorher-nachher-Strukturen eingeführt werden. ${ }^{549}$ In dieser performativen Sprechsituation können ebenfalls unterschiedliche Erzählweisen überblendet werden, wie die iterative und die singulative, wodurch es möglich wird, Zeiterfahrungen abzubilden, die sich grundsätzlich widersprechen.

In dieser Hinsicht grenzt sich Der Bau explizit von anderen Erzählformen ab. Wie in Robert Walsers Spaziergang gibt es hier einen Bezug zum Märchen als formaler Erzählreferenz, die nicht länger funktional ist. Nachdem der Erzähler sich eine rasche Lösung in Bezug auf das Zischen imaginiert hat, stellt er resigniert fest: „Ja in Märchen geht alles im Fluge und zu den Märchen gehört auch dieser Trost." (B 618) Das Märchen als traditionelle und prototypische Form der Erzählung wird als Gegensatz zum Erleben und Erzählen des Ich gesetzt. ${ }^{550}$ Im Gegensatz zum Märchen, das als lehrreiches Anschauungsmaterial, als metaphorische Anleitung zum richtigen Verhalten und in diesem Sinn als verschlüsseltes Vermitteln von Weltwissen und Identitätspolitik

549 So wird im Anschluss an die Ankunft auf dem Burgplatz plötzlich im Präteritum erzählt (B 6og).

550 Vgl. Ryan, „The Modes of Narrativity and Their Visual Metaphors“. 
angesehen werden kann, ist Der Bau ein Erzählen in einer gleichsam unendlichen Gegenwart, das sich in seiner Performanz selbst erzeugt und subvertiert. Damit formuliert Der Bau eine Position zum Ordnungsproblem, die das Märchen als einfache Erzählform von paradoxen, solipsistischen Erzählformen zur Etablierung von Ordnung und Identität ablöst.

Von diesem Punkt aus wäre auch eine Lektüre des Baus denkbar, die das Zunehmen des Zischens als Effekt dieser Verschiebung in der Erzählordnung hin zur Performanz versteht. Statt von einem Verstreichen von Zeit auszugehen, ließe sich eine zeitliche Konzentration, eine nach innen transportierte Zeit annehmen, die sich wie unter einem Mikroskop immer weiter ausdehnt. Das Erleben des Augenblicks bringt die Unendlichkeit des Augenblicks mit sich. Das Zischen wäre in dieser Lesart von Beginn der Erzählung an vorhanden, aber erst durch die Verschiebung und Fokussierung auf die Performanz des Jetzt würde es dominant. Gestützt wird diese Lektüre durch die Tatsache, dass mit dem Bau, der auf mehreren Ebenen selbst als Erzählung betrachtet werden kann, ein inhaltliches Pendant im Text gegeben ist. ${ }^{551}$ Die Sorge um die Qualität des Baus entspräche der Sorge um die Vollkommenheit der Erzählung; die Angst vor dem Eindringen eines Gegners ließe sich als Angst vor der Entschlüsselung der Erzählung durch den Leser verstehen. ${ }^{552}$ Wie beim Bau wäre

551 Vgl. dazu Alexander Honold, der zeigt, wie sich die figurative Darstellung des materiellen Schreibprozesses in zahlreichen Texten Kafkas nachweisen lässt. Honold, „Kafkas Trickster. Zum Auftritt des Fremden in der Schrift".

$55^{2}$ Vgl. dazu Bettina Menke, die in ihrer Lektüre den Bau als „Allegorie des Lesens, das heißt seiner Unlesbarkeit" bezeichnet und den Leser als Entsprechung des gefürchteten Tiers versteht. Menke, Prosopopoiia. Stimme und Text bei Brentano, Hoffmann, Kleist und Kafka, 9. Hervorhebung i. O. Der Text adressiert den Leser, wie der Bau den Feind adressiert und so in einem Doublebind auf diesen angewiesen ist: „Die Geste des Textes bringt Leser in die Position des ebenso gefürchteten, von der Konstruktion des Baus abzuwehrenden, wie von ihr vorausgesetzten Eindringlings; er wird zu dessen Analogon. Der literale ,Bau', dem es doch um Geheimhaltung im Abschluß nach außen geht, bedarf wie dessen Erzählung des bedrohenden oder bedrohlichen Eindringlings." Menke, 76 .

Die Grundlage dieser Lektüre bilden Deleuze und Guattaris Kleine Literaturen: „Aber das ist eine Falle, aufgestellt vom Tier und von Kafka selbst; die ganze Beschreibung des Baus dient nur zur Täuschung des Feindes. [...] Das Prinzip der vielen Eingänge behindert ja nur das Eindringen des Feindes, des Signifikanten; es verwirrt allenfalls jene, die ein Werk zu ,deuten' versuchen, das in Wahrheit nur experimentell erprobt sein will.“ Deleuze und Guattari, Kafka. Für eine kleine Literatur [franz. 1975], 7. Zentrum der These von Deleuze und Guattari ist die Ansicht, dass es sich bei Kafka und den „kleinen Literaturen“ nicht mehr um eine Frage der Semiotik handelt, sondern diese Entsprechung von Inhalt und Form in der Folge des Poststrukturalismus überschritten wird: „Was wir vor uns haben, ist also keine strukturelle Entsprechung zweier Formen, der des Inhalts und der des Ausdrucks, sondern eine Ausdrucksmaschine, die sowohl ihre eigenen Formen als auch die des Inhalts desorganisiert, um reine Inhalte freizusetzen, die sich mit den Ausdrücken in ein 
es auch in Bezug auf die Erzählung irgendwann zu spät, um neu anzufangen; das Vorhandene lässt fundamentale Änderungen nicht mehr zu. Einem Text vergleichbar ist der Bau (und Der Bau) prinzipiell unabschließbar. Zwar ist er „eingerichtet" und scheinbar „wohlgelungen“ (B 576), doch die Arbeit an den Details ist endlos.

Diese metaphorisch ausgerichtete Lektüre hebt den statischen, bildhaften Aspekt des Baus hervor, dem die Dynamik der narrativen Entfaltung des Textes und insbesondere dessen performative Verschiebung gegenüber steht. ${ }^{553}$ Die Modelle der "gleitenden Metapher" ${ }^{\text {“54 }}$ bzw. des "gleitenden Paradoxes“555 greifen insofern zu kurz, als sie mit dem Fokus auf die Verfahren der Semantik die Ebene des Erzählens ausklammern und so statt der Verschiebungen im Erzählen die Bedeutungsverschiebungen der Semantik betonen. Diese Performanz der Erzählverfahren im Bau ist auch inhaltlich formuliert: Es ist die „Einbildungskraft" (B 622), die Ursprung und Ursache der Handlungen und des Erzählens des Ich ist. ${ }^{556}$

\subsection{Kafkas unmögliches Erzählen. Fazit}

In zahlreichen Texten Franz Kafkas ist Ordnung ein zentrales Thema. Die dominante räumliche und architektonische Figuration findet par excellence in Der Bau Anwendung. Im Zentrum der Erzählung steht eine Figur, die

und demselben Intensivstoff vermischen. Große oder etablierte Literaturen folgen einer Linie, die sie vom Inhalt zum Ausdruck führt: Sie müssen für einen gegebenen Inhalt in gegebener Form die passende Ausdrucksform finden, entdecken, sehen. Was man gut begriffen hat, kann man auch gut sagen. - Die ,kleine‘ oder revolutionäre Literatur indessen beginnt mit dem Sagen und sieht oder begreift erst später (,Ich sehe das Wort überhaupt nicht, das erfinde ich'). Der Ausdruck muß die Formen zerbrechen, die Bruchstellen und neuen Verzweigungen angeben. Ist eine Form dann zerbrochen, so gilt es, den Inhalt zu rekonstruieren, der zwangsläufig mit der Ordnung der Dinge im Bruch sein wird. Den Stoff mit sich fortreißen, ihm vorauseilen." Deleuze und Guattari, 40. Hervorhebung i. O.

Auch Robert Walser gebraucht den Vergleich des Schreibens mit dem Graben: „Sie [die Schriftsteller] legen gern von Zeit zu Zeit die Feder ein wenig aus der Hand. Anhaltendes Schreiben ermüdet wie Erdarbeit." (KWA I.8, 189)

553 Vgl. dazu auch Niehaus, der davon ausgeht, „dass Kafkas Texte zu iterativen Formen tendieren, weil das Schreiben für Kafka eine Form des Denkens ist: Der Vorgang des Schreibens gleicht der Erkundung einer Sache - eines Zustandes, einer Struktur, eines Verhältnisses.“ Niehaus, „Iterativität bei Kafka. Vorläufige Bemerkungen“, 113. Hervorhebung i. O.

554 Vgl. Hiebel, Franz Kafka.

555 Vgl. Neumann, „Umkehrung und Ablenkung. Franz Kafkas, Gleitendes Paradox“ [1968]“.

$55^{6}$ Siehe Kap. 4.1.3 Der panische Plan und die geplante Panik, S. 216ff. unten. 
zahlreichen Ordnungskriterien widersteht und ambivalent konnotiert ist. Der Kontingenz im Bau ist das Erzähler-Ich in einem Doublebind aus Planung und Panik ausgeliefert. In Der Bau wird angedeutet, was bei Robert Walser auffällig kenntlich ist: Ordnung wird performativ im Erzählen erzeugt. Neben der vielfach betonten Prekarisierung der semantischen Ordnung, die Kafka mittels konstanter Bedeutungsverschiebung von Begriffen und Bildern praktiziert, ist die prekäre Erzählanlage hervorzuheben. Die Geschichte, die sich auf das Ordnungsproblem der Moderne bezieht, wird mit einem ,unmöglichen', konstitutiv ambivalenten Erzähler, diskontinuierlicher Zeit und ambivalenter Ereignishaftigkeit erzählt. In dieser konzeptuellen Herangehensweise an die Ordnung lässt sich, im Gegensatz zu Walser, ein paradoxes, spiralförmiges Graben feststellen, das seinen Grund, so unmöglich wie das Erzählen, immer selbst erzeugen muss. Die Vieldeutigkeit und Ambivalenz ist nicht nur auf einer symbolisch-semantischen Ebene für den Bau konstitutiv, sondern auch auf der Ebene des Erzählens als Ordnungsverfahren selbst. Das Prekäre an Kafkas Erzählen besteht also auf formaler Ebene in der aporetischen Erzählsituation, der widersprüchlichen Raum- und Zeitkonstruktion und auf inhaltlicher Ebene in ambivalenten Zuschreibungen und Ordnungsfigurationen. 